Images Re-vues

re-VUES

Histoire, anthropologie et théorie de l'art

Figurer les invisibles

\title{
Bill Viola ou l'image sans représentation
}

\section{Chiara Cappelletto}

\section{OpenEdition}

\section{Journals}

Édition électronique

URL : http://journals.openedition.org/imagesrevues/497

DOI : 10.4000/imagesrevues.497

ISSN : 1778-3801

\section{Éditeur :}

Centre d'Histoire et Théorie des Arts, Groupe d'Anthropologie Historique de l'Occident Médiéval,

Laboratoire d'Anthropologie Sociale, UMR 8210 Anthropologie et Histoire des Mondes Antiques

\section{Référence électronique}

Chiara Cappelletto, «Bill Viola ou l'image sans représentation », Images Re-vues [En ligne], 8 | 2011, mis en ligne le 20 avril 2011, consulté le 02 mars 2021. URL : http://journals.openedition.org/

imagesrevues/497; DOI : https://doi.org/10.4000/imagesrevues.497

\section{(9) $(1) \Theta$}

Images Re-vues est mise à disposition selon les termes de la Licence Creative Commons Attribution Pas d'Utilisation Commerciale 4.0 International. 


\title{
BILL VIOLA OU L’IMAGE SANS REPRESENTATION
}

\author{
Chiara Cappelletto
}

\begin{abstract}
Bill Viola affirme que l'ère de la vision optique est terminée et, malgré cela, ses œuvres donnent l'impression d'une parfaite évidence visuelle: ce paradoxe d'une image non destinée à la vue est le thème de cet article. La première thèse développée grâce à la comparaison de la production du vidéaste avec l'art figuratif et le théâtre est qu'elle a une autonomie esthétique spécifique qui se fonde sur l'élision préalable du seuil de la fiction. La deuxième thèse est que $\mathrm{B}$. Viola propose à nouveau la conception de cet axil innocent dont on pensait qu'il n'existait pas, sous la forme d'un corps sincère dont l'existence reste encore à prouver. Il crée en effet des configurations audiovisuelles qui permettent, par la mise en avant de l'expressivité originaire de l'homme, de produire un effet persuasif, affirmatif même, sur le spectateur qu'il soit naïf ou sophistiqué tout en sollicitant son système nerveux. La troisième thèse est que dans toute sa production est à l'œuvre le même problème esthétique, à savoir le délitement de l'identité psychologique du spectateur qui fait l'expérience sur lui-même du véritable thème des vidéos : l'émotion. Ces images vont alors s'incorporer dans l'homme.
\end{abstract}

\section{Tradition picturale et déclin de la vision optique}

« Nous atteignons la fin de l'ère de la vision optique. Aujourd'hui, ce que l'œil voit ne doit pas nécessairement être pris pour une chose réelle. La réalité est submergée par des informations incorporées en nous. C'est pourquoi ce qui est subjectif est en train de devenir la nouvelle objectivité ». C'est ce qu'a affirmé Bill Viola dans un entretien filmé lors de sa résidence au MIT au printemps 2009, à l'occasion de l'Eugene McDermott Award in the Arts qui lui avait été décerné. La suprématie exclusive de la dimension optique est sur le point de se terminer : c'est une conviction qui gagne du terrain lorsque l'on observe les plus récentes façons d'aborder les images produites par les médias contemporains, pas seulement artistiques. Ces images sont issues de technologies qui mettent principalement en ouvre la kinesthésie et le sens du toucher associé à la vue. L'affirmation de B. Viola n'est par conséquent pas significative en soi ; ce qui est cependant frappant, c'est qu'on la doit au vidéaste le plus connu actuellement et dont les derniers travaux atteignent une extrême précision dans la définition du contour des corps filmés, produisant un fort effet de présence sur le spectateur selon l'alliance, ancienne bien que controversée, entre l'apparence d'un objet et son concept.

Diplômé en 1973 de la Syracuse University, B. Viola travailla dans cette même ville en tant que technicien vidéo à l'Everson Museum qui - sous la direction de David Ross ouvrit ses portes à l'art vidéo (le magnétoscope était alors né moins de dix ans auparavant et le caméscope Portapak de Sony avait à peine été commercialisé). Il est l'un des pionniers de cette forme artistique, suivant de peu Fluxus, Nam June Paik, Vito Acconci, Bruce Nauman, Peter Campus, Frank Gillette. Comparé à eux cependant, B. Viola a gagné aujourd'hui une renommée qui fut rarement accordée à un artiste et qui dépend - en partie au moins - de l'apparente facilité avec laquelle chaque spectateur, du plus naïf au plus sophistiqué, croit pouvoir regarder et comprendre immédiatement les images du cycle The Passions, le plus 
connu, qui exhibent un élément iconique d'autant plus saisissable qu'il donne l'impression d'une parfaite évidence optique : elle lierait le spectateur émotionnellement, le jetant dans un état d'émotion pure et absolue en réponse directe à ce qu'il voit.

The Passions est le fruit des recherches menées par B. Viola en 1998 à l'initiative de Salvatore Settis, alors directeur du Getty Research Institute, qui lui proposa d'explorer la représentation des passions. Les différentes œuvres du cycle mettent en scène la façon de représenter l'apogée des émotions: The Quintet Series (The Quintet of the Astonished, The Quintet of Remembrance, The Quintet of the Silent, The Quintet of the Unseen [fig.1]) (2000), Dolorosa (2000) (fig.2), Anima (2000) (fig.3), The Locked Garden (2000) (fig.4), Six Heads (2000), Memoria (2000), Union (2000), Witness (2001), Man of Sorrows (2001), Unspoken (2001), Mater (2001), Four Hands (2001), Catherine's Room (2001), Silent Mountain (2001) (fig.5), Surrender (2001), Five Angels for the Millenium (2001) (fig.6), Emergence (2002), Observance (2002).

Fig.1.

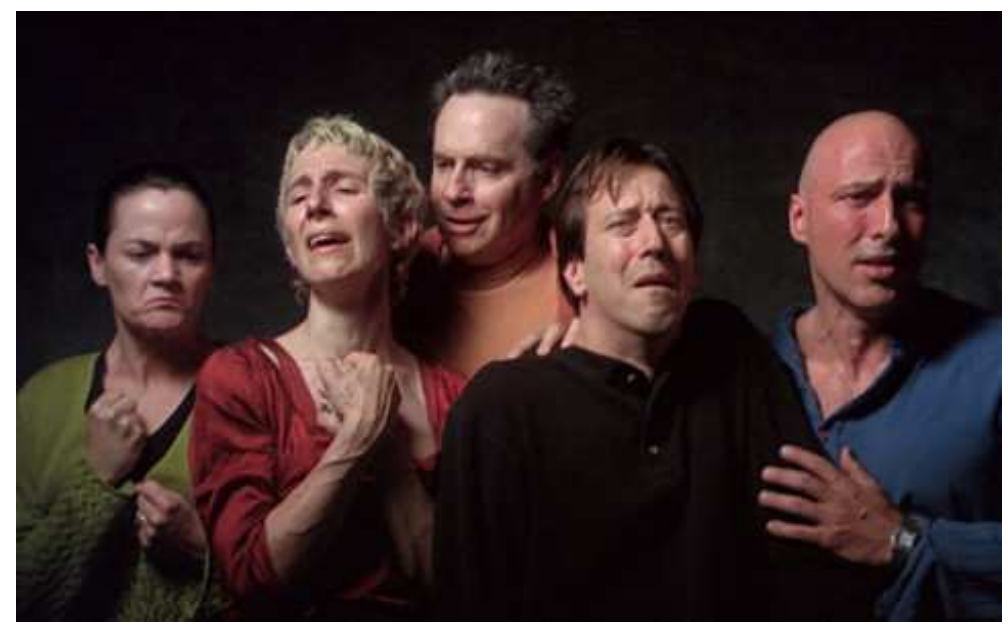

Bill Viola, The Quintet of the Unseen, 2000

photographie : Kira Perov

Fig.2.

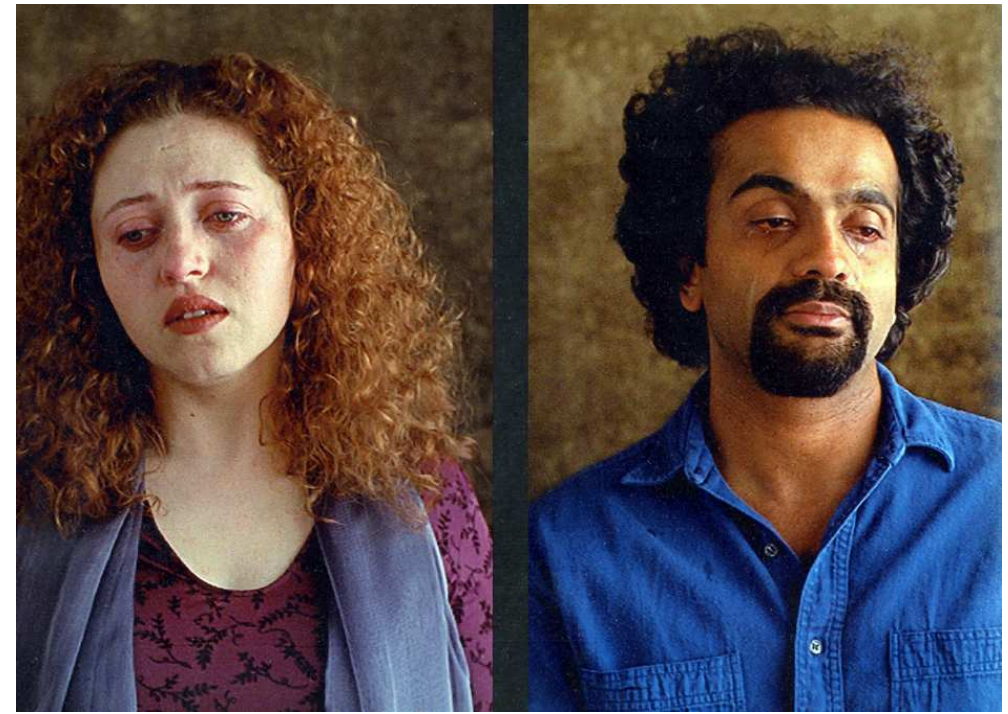

Bill Viola, Dolorosa, 2000

in K. Perov (dir.), Bill Viola. Visioni Interiori, cat. exp. Palazzo delle Esposizioni, Rome, 21 octobre $2008-6$ janvier 2009, Rome, Giunti, 2008, p. 58 
Fig.3.
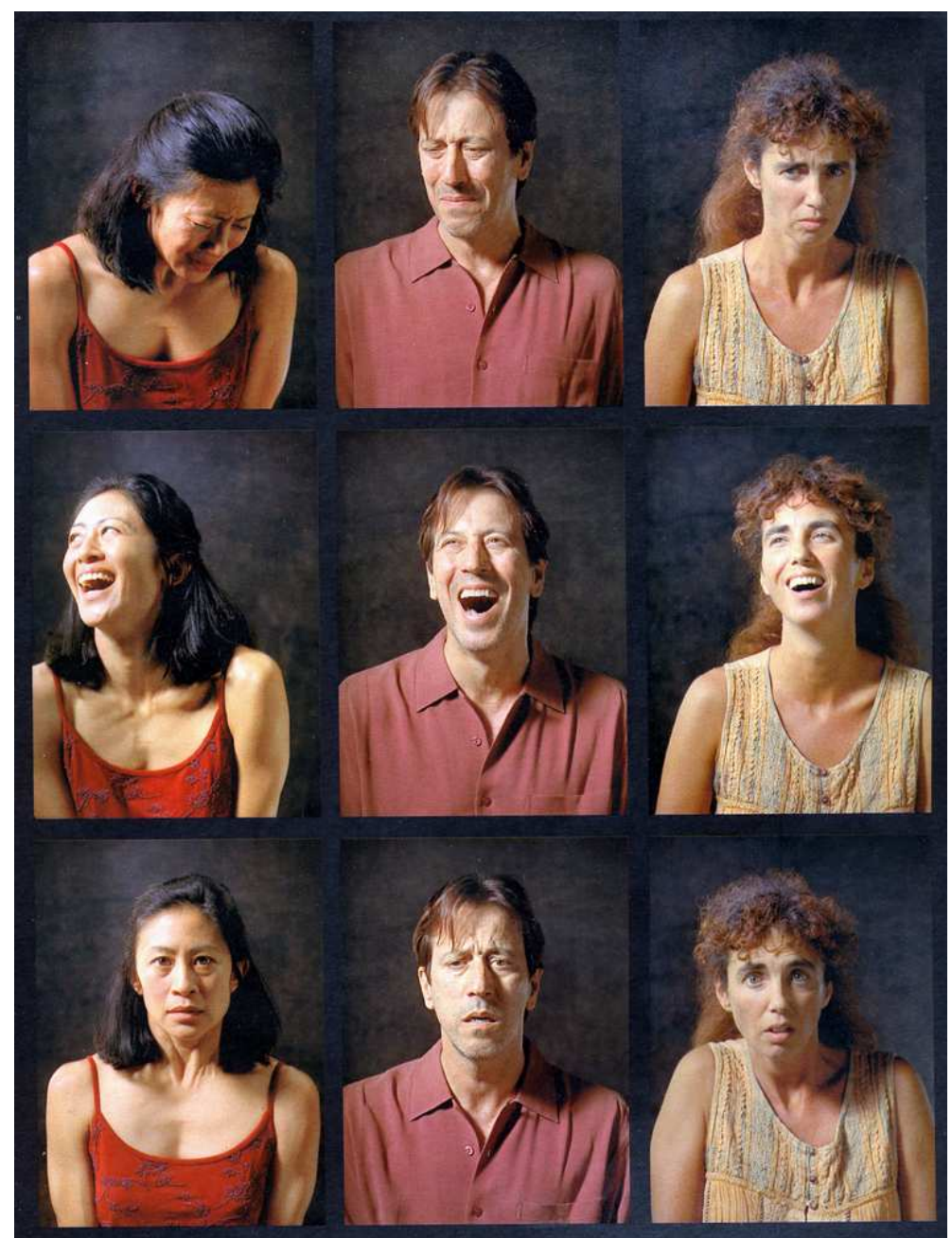

Bill Viola, Anima, 2000

in K. Perov, Bill Viola. Visioni Interiori, op.cit., p. 93

Fig.4.

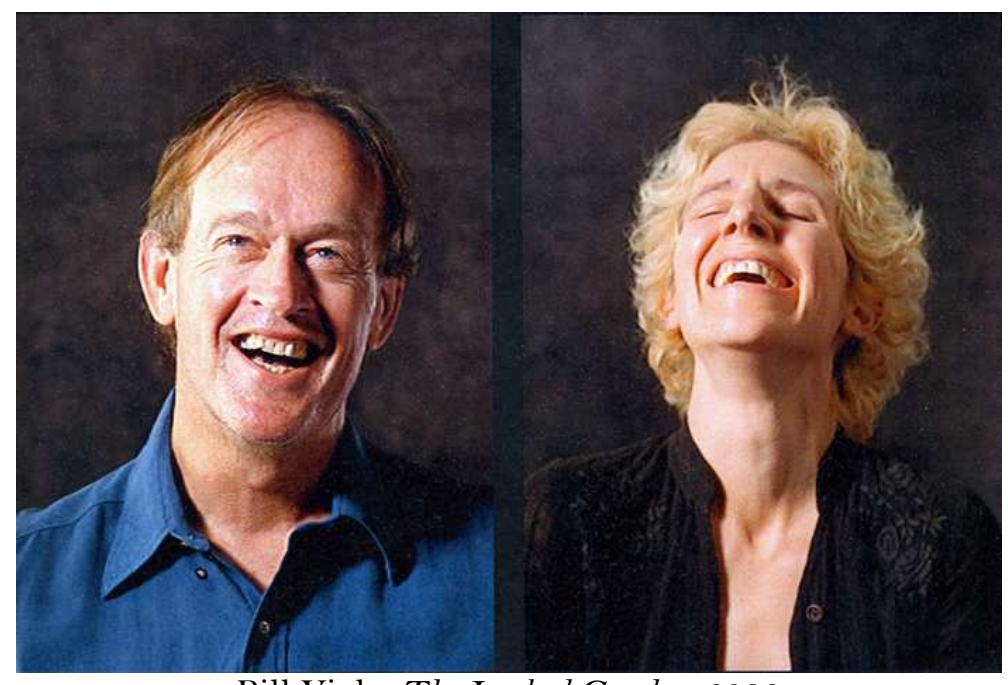

Bill Viola, The Locked Garden, 2000

in K. Perov, Bill Viola. Visioni Interiori, op.cit., p. 66 
Fig.5.

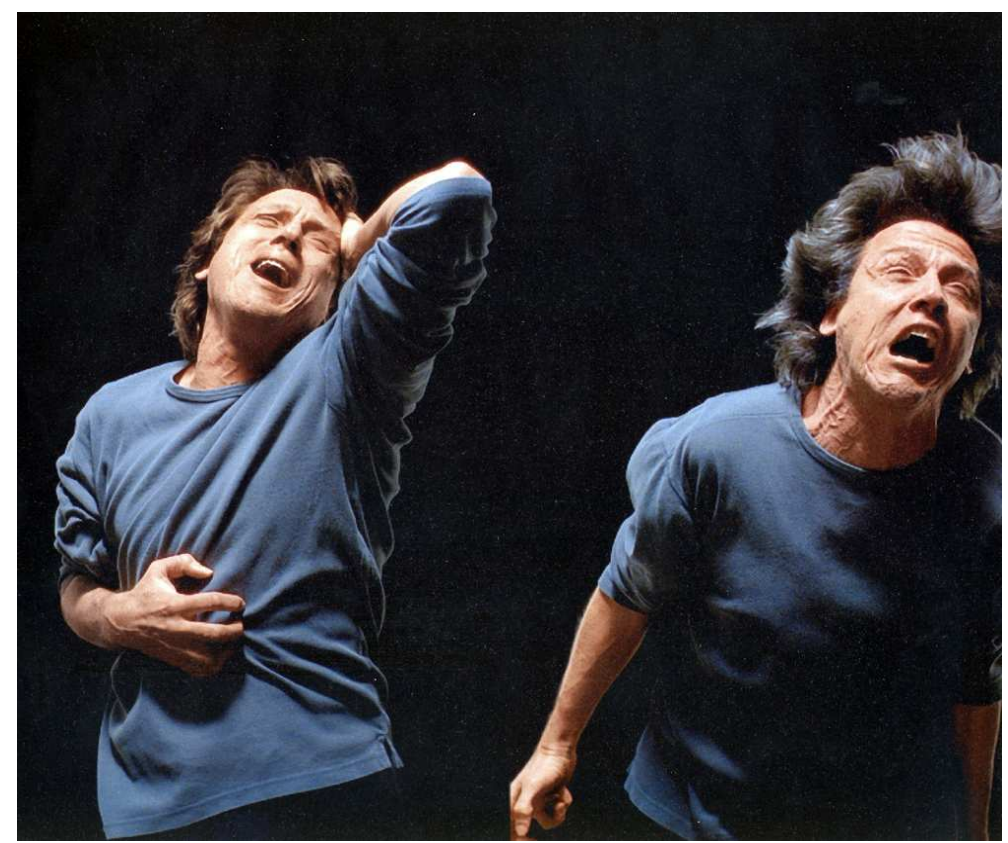

Bill Viola, Silent Mountain, 2001

in K. Perov, Bill Viola. Visioni Interiori, op.cit., p. 99

Fig.6.

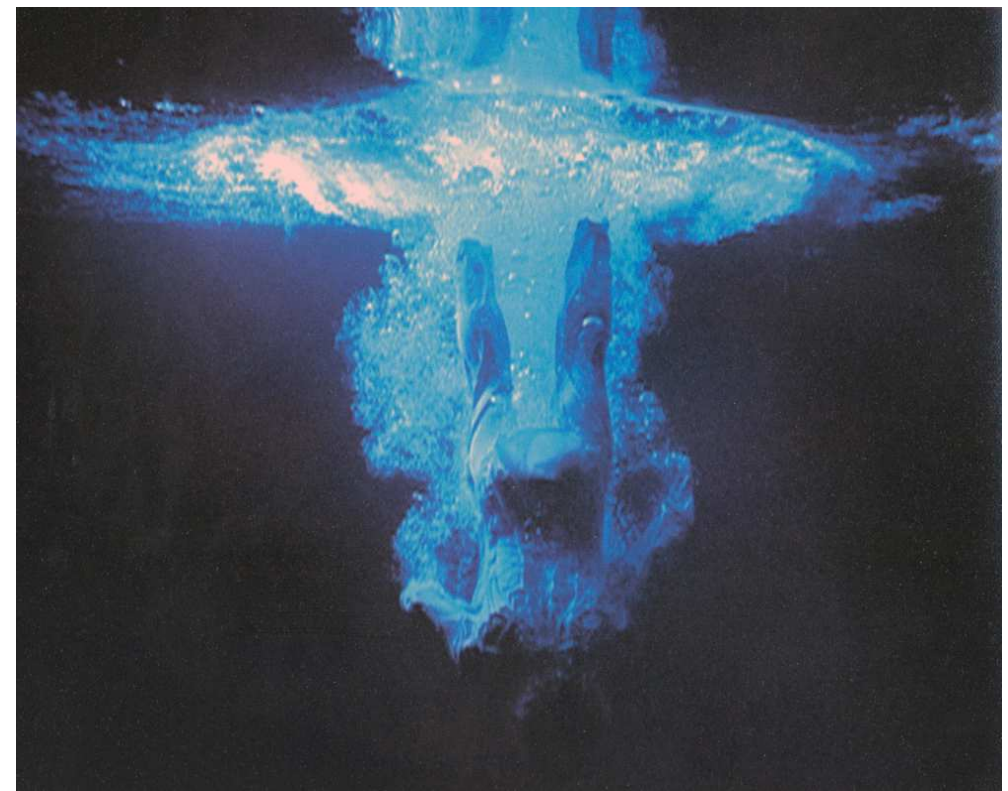

Bill Viola, Five Angels for the Millenium, 2001

in K. Perov, Bill Viola. Visioni Interiori, op.cit., p. 74

Parmi les instruments dont B. Viola s'est servi durant ces années, il faut mentionner les dessins réalisés par Charles Le Brun en 1698 pour illustrer L'Expression des Passions ainsi que l'ouvrage de Charles Darwin L'Expression des Émotions chez l'Homme et chez les Animaux (1872) et l'essai que Jennifer Montagu rédigea en 1994, The Expression of the Passions. The Origin and Influence of Charles Le Brun's "Conférence sur l'expression générale et particulière". Parmi les tableaux qu'il a observés avec attention et à plusieurs reprises lors de sa recherche, il cite l'Annonciation de Dieric Bouts (1450-1455) et L'Adoration des Mages de Mantegna (c. 1495-1505) (fig.7). The Quintet of the Astonished (fig.8) doit beaucoup à cette dernière 
œeuvre et renvoie également à un second tableau, le Christ aux Outrages de Hieronymous Bosch (1490-1500)1 (fig.9). Devant ce tableau, il prend note :

Quintet of the Astonished: regroupement étrange mais soigné, rapport horizontal, prises de vues accélérées, éclairage délicat, vestiaire par types de caractère, le Christ aux Outrages de Bosch à la National Gallery de Londres : émergent en surface des émotions et des relations changeantes. Chacun déploie un éventail d'émotions conflictuelles allant du rire aux larmes, filmé avec des prises de vues accélérées, vu en haute définition, originaire, hyperréel. Les émotions vont et viennent si graduellement qu’il est difficile de dire où commence l'une et où disparaît l'autre. Les relations entre les figures deviennent fluides et changeantes².

\section{Fig.7.}

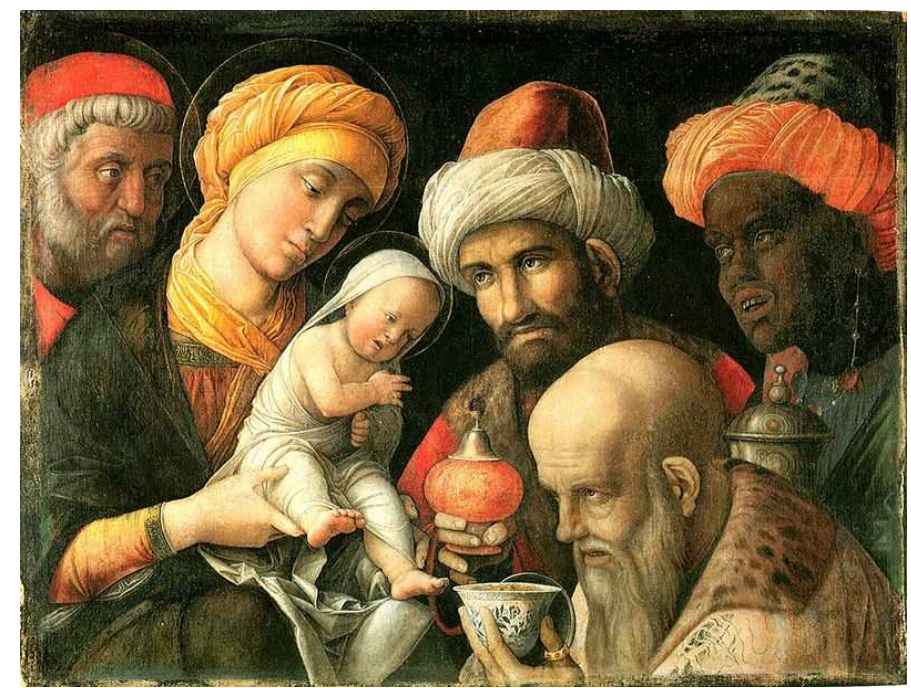

Andrea Mantegna, L'Adoration des Mages, c. 1495-1505. Huile sur toile, Los Angeles, The J. Paul Getty Museum

Fig.8.

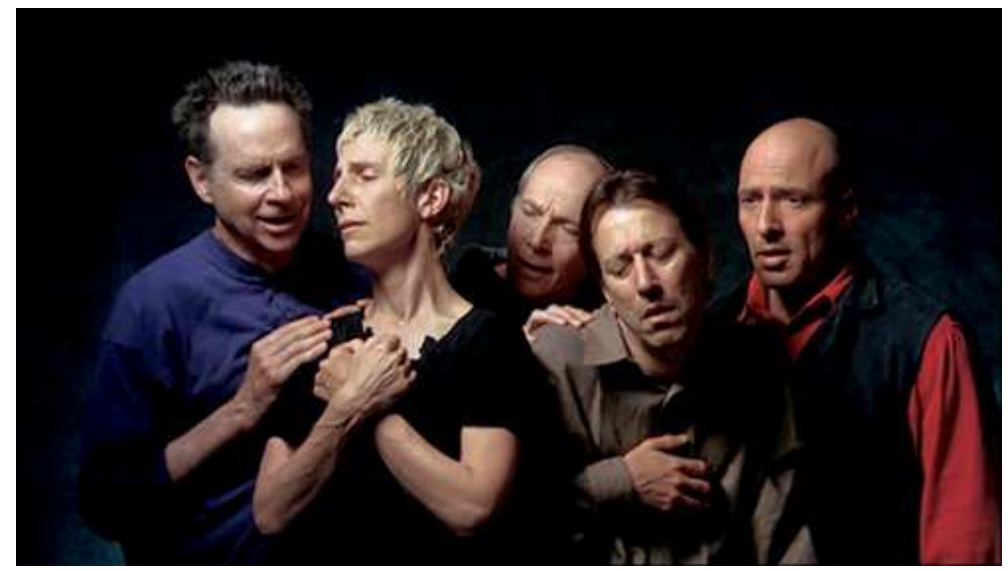

Bill Viola, The Quintet of the Astonished, 2000

photographie : Kira Perov

\footnotetext{
${ }^{1}$ Bill Viola voit ce tableau à la National Gallery de Londres, où, toujours en 1998, il fut invité à participer à l'exposition «Encounters». Je tiens à remercier ici Valentina Valentini pour ses généreuses indications bibliographiques et la relecture attentive qu'elle fit de cet essai dans sa version première. Je tiens aussi à remercier vivement Katia Bienvenu à qui la version française de ce texte doit beaucoup.

${ }^{2}$ Cité dans J. Walsh, «Emotions in extreme time. Bill Viola’s Passions project », in J. Walsh (dir.), Bill Viola. The Passions, cat. exp. J. Paul Getty Museum, 24 janvier-27 avril 2003, Getty Publications, Los Angeles, 2003, p. 25-63, ici p. 33.
} 
Fig.9.

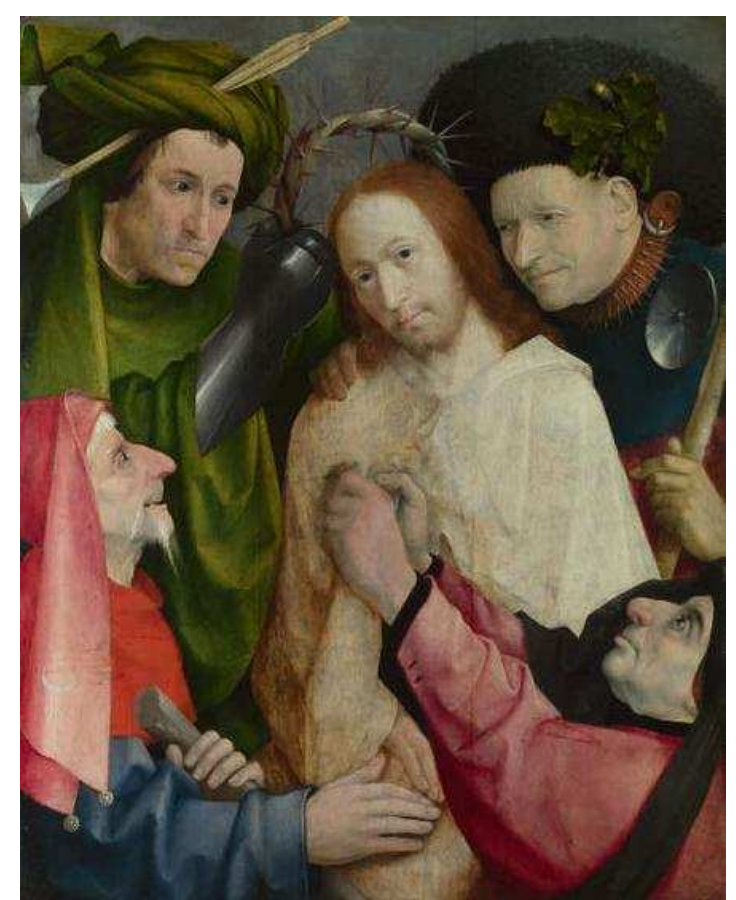

Hieronymous Bosch, Christ aux Outrages (Le Couronnement d'Épines), 1490-1500. Huile sur bois, Londres, National Gallery

Le lien entre les vidéos de The Passions et certaines ouvres de la peinture européenne du XV $\mathrm{XV}^{\mathrm{e}} \mathrm{XVI} \mathrm{I}^{\mathrm{e}}$ siècle a été ramené par $\mathrm{S}$. Settis à des critères tels que le format, le choix du sujet, la représentation du mouvement. On voit le premier critère en action dans Catherine's Room (fig. 10), qui fait référence à Sainte Catherine de Sienne et Quatre Sceurs du Tiers-Ordre Dominicain d'Andrea di Bartolo (c. 1393-1394) (fig.11), dont il réutilise la forme de la prédelle. Le second critère est visible dans Emergence (fig.12) qui reprend le sujet et la structure dramaturgique de la Pietà de Masolino (1424) (fig.13). On retrouve le troisième dans The Greeting ${ }^{3}$ (fig.14), l'œuvre qui renvoie à la Visitation de Pontormo (1528-1529)4 (fig.15). J. Walsh a en outre rappelé comment Observance prend également pour point de départ un chef-d'œuvre de la tradition picturale, Les Quatre Apôtres de Dürer (1526), une forme qu'il délaissera par la suite ${ }^{5}$.

\footnotetext{
${ }^{3}$ Dans cette vidéo réalisée en 1995, B. Viola s’interroge déjà sur l'expression de l'émotion et introduit une nouvelle méthode de travail nécessitant de choisir des acteurs.

${ }_{4}^{4}$ Pour la reconstruction complète des corrélations entre la peinture et la vidéo chez B. Viola, voir S. Settis, «Bill Viola : i conti con l'arte », in K. Perov (dir.), Bill Viola. Visioni Interiori, cat. exp. Palazzo delle Esposizioni, Rome, 21 octobre 2008 - 6 janvier 2009, Rome, Giunti 2008, p. 14-35.

${ }^{5}$ Voir J. Walsh, « Emotions in extreme time. Bill Viola’s Passions project », art.cit..
} 
Fig.10.
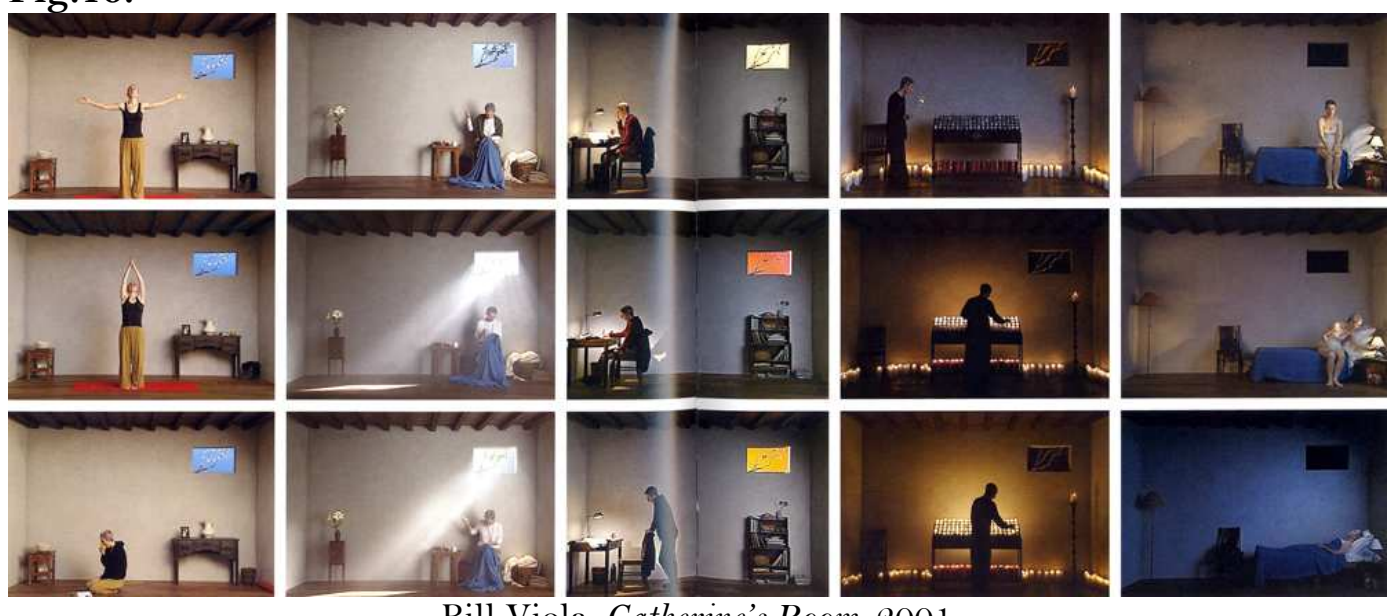

Bill Viola, Catherine's Room, 2001

in K. Perov, Bill Viola. Visioni Interiori, op.cit., p. 84-85

Fig.11.

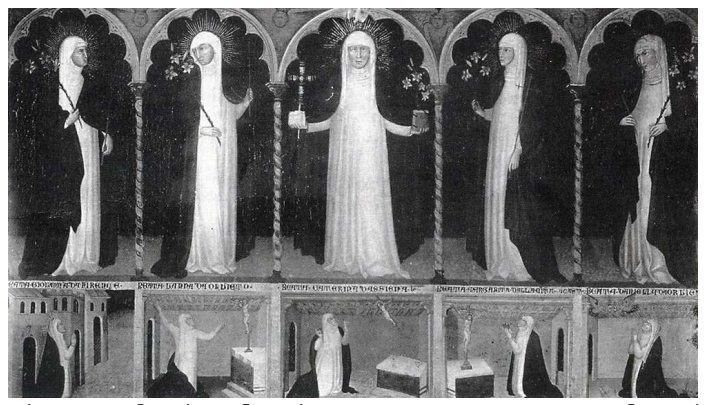

Andrea di Bartolo, Sainte Catherine de Sienne et Quatre Scurs du Tiers-Ordre Dominicain, 1393-1394. Tempera sur panneau, Murano, Museo Vetrario

in K. Perov, Bill Viola. Visioni Interiori, op.cit., p. 22

Fig.12.

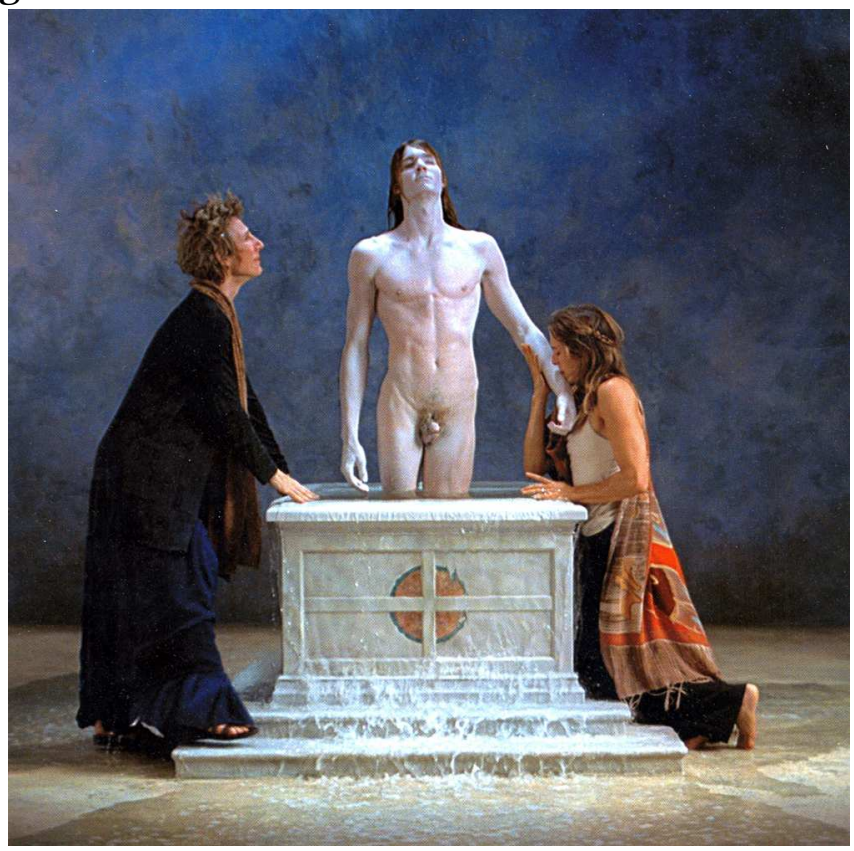

Bill Viola, Emergence, 2002

in K. Perov, Bill Viola. Visioni Interiori, op.cit., p. 103
Fig.13.

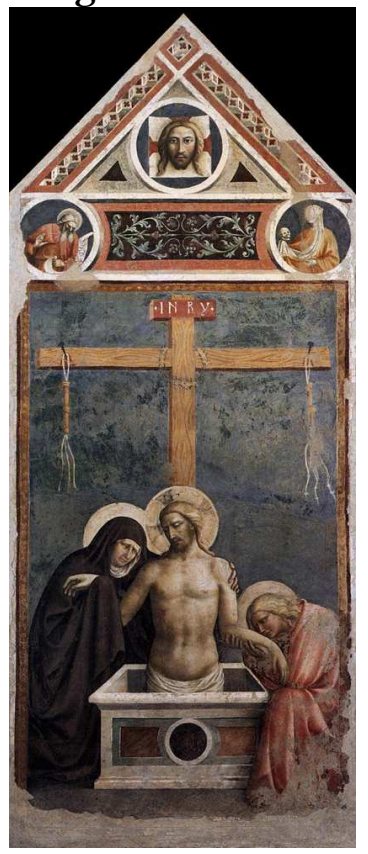

Tommaso Masolino da Panicale, Pietà, 1424.

Fresque, Empoli, Museo della Collegiata di Sant' Andrea 
Fig.14.

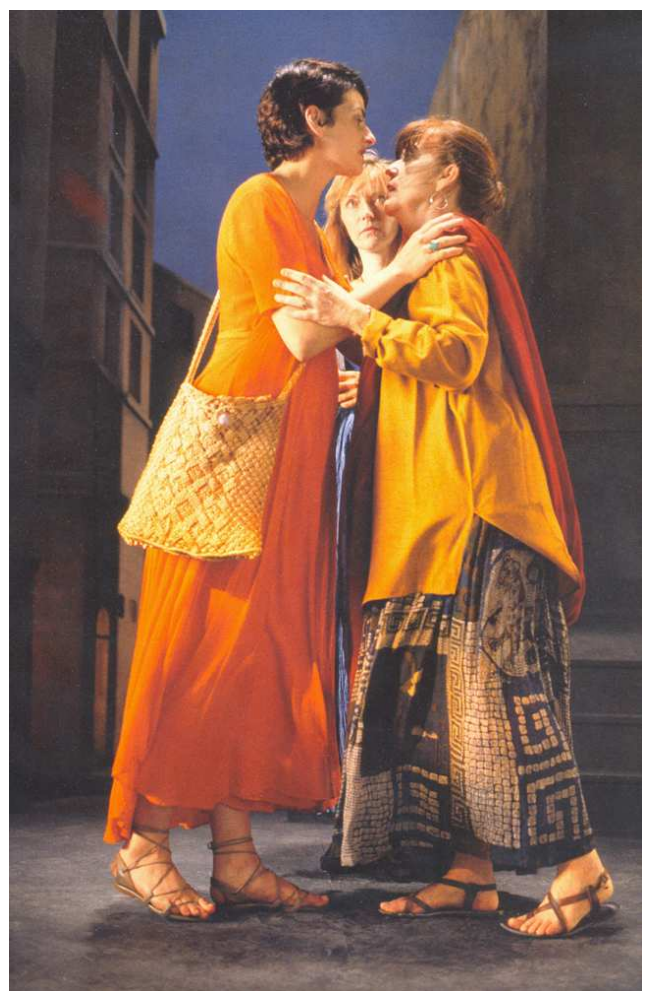

Bill Viola, The Greeting, 1995

in K. Perov, Bill Viola. Visioni Interiori, op.cit., p. 41

Fig.15.

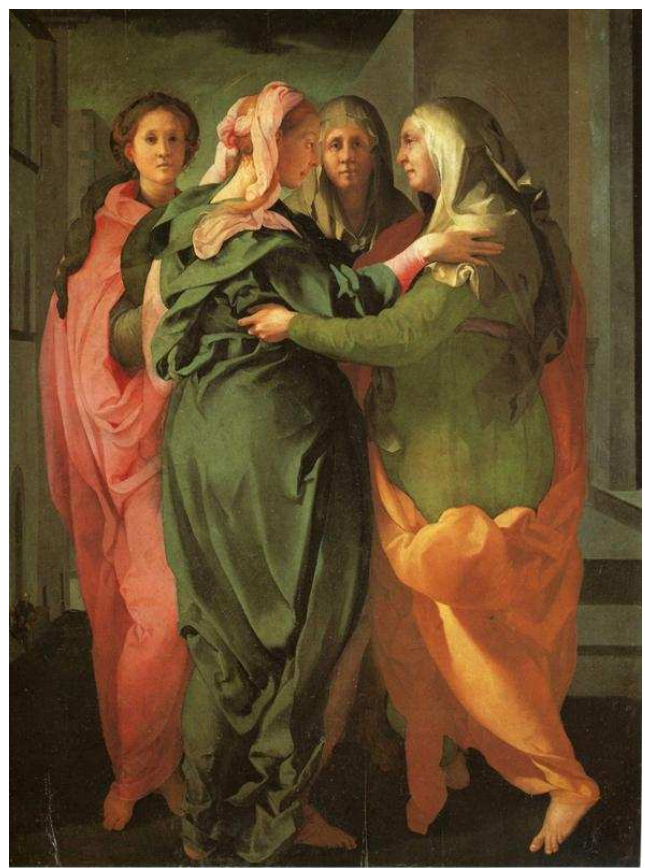

Pontormo, Visitation, 1528-1529.

Huile sur bois, Carmignano, église de San Michele

De telles récurrences formelles sembleraient confirmer la dette de B. Viola envers les règles de la perception visuelle et la façon dont celle-ci a été ordonnée par la tradition picturale occidentale. S. Settis écrit en effet que B. Viola est 
en tout point un "peintre"; il a réglé ses comptes, et continue de le faire, avec l'art, avec la tradition, et dans ses œuvres, il engage avec l'observateur un dialogue qui présuppose la référence aux formats, aux sujets, aux compositions, à la gestuelle, aux mouvements et aux artifices expressifs ou narratifs qui possèdent un enracinement solide et lointain dans l'histoire qui l'a (qui nous a) précédé 6 .

C'est sans aucun doute vrai concernant la disposition et la proxémie des figures dans les ouvres du cycle, et pour écarter le moindre doute, il suffirait de regarder Six Heads, une véritable « étude » de six expressions faciales ${ }^{7}$ inspirée d'un passage trouvé par B. Viola dans le livre de Victor Stoichita sur les expériences visionnaires de l'art espagnol du XVII ${ }^{\mathrm{e}}$ siècle $^{8}$, qui renvoie aux peintures de José Ribera montrant des saints en proie à l'extase, sans que ce qui suscite l'extase ne soit cependant visible pour le spectateur. Une autre «étude », Four Hands (fig.16), lui fut suggérée par une planche représentant des mains (fig.17) datant de la même période, elle aussi reproduite dans le livre de V. Stoichita ${ }^{9}$ : quatre paires de mains d'enfant, de femme, d'homme, de femme âgée - projetées sur quatre écrans distincts et disposées en enfilade alors que chacun accomplit différentes séquences de gestes.

\section{Fig.16.}

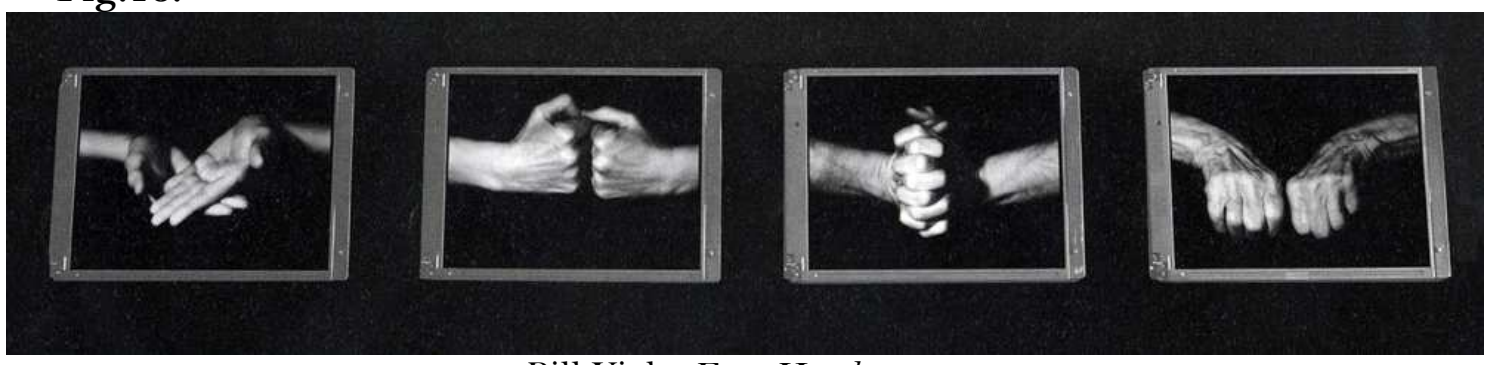

Bill Viola, Four Hands, 2001

in K. Perov, Bill Viola. Visioni Interiori, op.cit., p. 86

Fig.17.

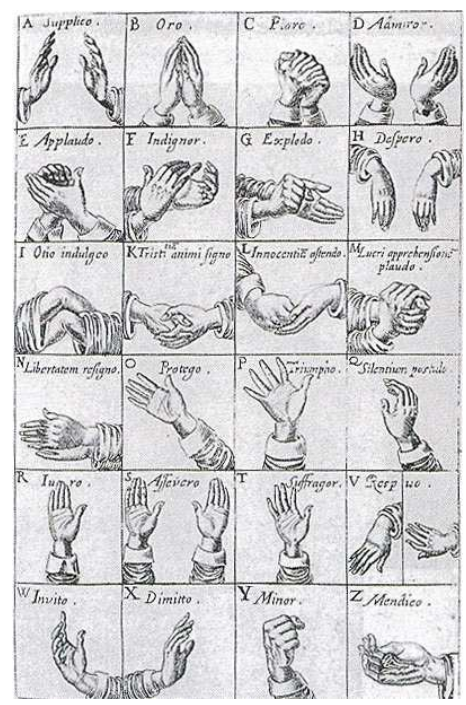

Planche de John Bulwer, Chirologia, or the Natural Language of the Hand, 1644.

Londres, British Library

\footnotetext{
${ }^{6}$ S. Settis, « Bill Viola : i conti con l'arte », art.cit., p. 20.

${ }^{7}$ Elles sont ordonnées en deux files de trois et placées devant un fond sombre sans contexte ni décor.

${ }^{8}$ V. Stoichita, Visionary Experience in the Golden Age of Spanish Art, Londres, Reaktion Books, 1995.

9 Voir J. Walsh, «Emotions in extreme time. Bill Viola’s Passions project », art.cit..
} 
B. Viola semble avoir pour sa part une conscience très précise de son propre rapport à l'histoire de l'art. Lorsqu'il fait référence à la typologie formelle du triptyque dans Nantes Triptych (1992) (fig.18) par exemple, il affirme qu'il est plus intéressé par cette forme parce qu'elle fait partie du bagage culturel de ceux qui connaissent l'Europe, que par la citation ou la saisie d'une "image d'emprunt" [car selon lui] si l'on va trop loin dans cette voie, il est facile de se laisser séduire par le processus de citation en soi et pour soi, et on finit par ne plus avoir de respect pour la puissance intrinsèque des objets et des matériaux mêmes, et pour leurs potentialités de transformation intérieure qui constituent le motif originaire permettant de s'en approprier ${ }^{10}$.

Fig.18.

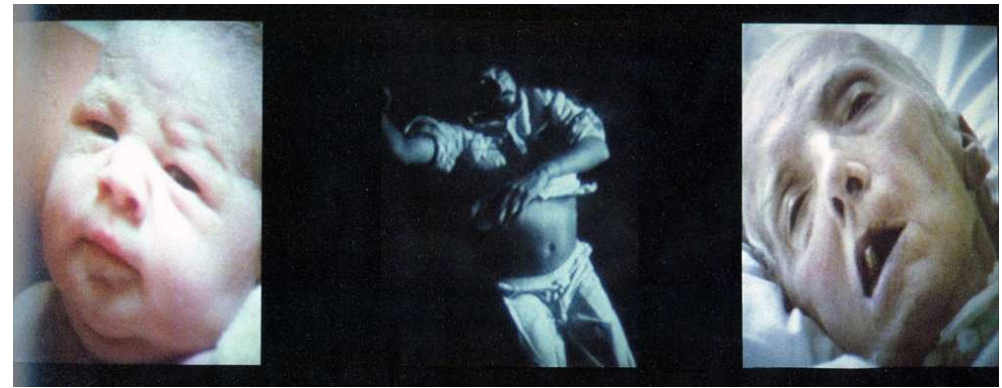

Bill Viola, Nantes Triptych, 1992

in K. Perov, Bill Viola. Visioni Interiori, op.cit., p. 169

Ce sont par conséquent à la fois le pouvoir latent de la forme visuelle et la manière dont une large partie du public lui répond involontairement qui l'intéressent, indépendamment des réflexions concernant une quelconque philosophie de l'histoire.

L'attention au pouvoir énergétique interne à une composition est telle que $\mathrm{S}$. Settis a raison lorsqu'il remarque que dans Emergence, l'important n'est pas tant que « le jeune qui émerge de l'eau ne soit pas le Christ [mais le fait] qu'il pourrait l'être ». Il ne me semble cependant pas envisageable d'en déduire, avec l'historien de l'art, qu'une telle puissance évocatrice puisse conférer à la scène

une épaisseur rituelle qui sacralise l'expérience et les émotions de l'observateur, parce qu'elle les enracine dans une mémoire culturelle longue et tenace, qui devient d'autant plus tenace lorsque l'on veut la réfuter. La dimension historique implicite de l'approche, à la fois visionnaire et critique de Bill Viola, intensifie l'épaisseur de la représentation, mais aussi les émotions de l'observateur ${ }^{11}$.

Sans pour autant sous-estimer la capacité de survivance de la mémoire et l'actualisation des expériences mnémoniques qui appartiennent à l'art figuratif, l'hypothèse que j'avance est que la dimension historique implicite que S. Settis reconnaît ici, en la mettant d'une manière cohérente en rapport avec un système de construction représentative interne à l'image, manque dans des travaux pour lesquels la temporalité est envisagée comme un éternel présent. Le spectateur est en effet appelé à y répondre, avant tout mécaniquement, en terme de réactivité physique et non en terme d'éducation visuelle, culturelle et symbolique. Comme nous le verrons, B. Viola propose à nouveau, selon moi, la conception de cet ail innocent dont on pensait qu'il n'existait pas, sous la forme d'un corps sincère dont l'existence reste encore à prouver.

\footnotetext{
${ }^{10}$ B. Viola, «In risposta alle domande di Jörg Zutter », in Visioni Interiori, op.cit., p. 176-191, ici p. 183-184. $B$. Viola ajoute que la structure du triptyque est une triade sociale et cosmologique qui possède selon lui une capacité descriptive en mesure de libérer de nouvelles énergies dans des images contemporaines.

${ }^{11}$ S. Settis, « Bill Viola : i conti con l’arte », art.cit., p. 26.
} 
Il est vrai que dès les premières vidéos, il adopte des solutions figuratives qui sont semblables à celles de la production picturale européenne. J'en citerai quelques exemples éloquents : dans Sweet Light (1977), la boule de papier blanc chiffonné et jetée par terre d'où surgit une phalène et sur laquelle la caméra fait un zoom (fig.19) rappelle les roches peintes par Giotto (fig.20), artiste cité et apprécié par le vidéaste dont il dit avoir appris le rapport entre l'irréalité figurative et la réalité intérieure du spectateur ${ }^{12}$. Nous retrouverons la même forme de montagne hyperréelle au centre d'une longue séquence de Hatsu-Yume First Dream (1981) pendant laquelle le bloc rocheux, dans sa fixité, s'impose par rapport aux individus qui, luttant péniblement contre le vent, se déplacent autour de lui (fig.2 1a). Dans la séquence qui suit, la prise de vue floue d'une surface rouge et blanche ondoyante (fig.21b) - nous comprendrons qu'il s'agit d'un poisson dans l'eau quand finalement la mise au point de l'image sera faite - reproduit précisément l'impression de flottement des drapeaux français de La Rue Montorgueil (1878) de Monet (fig.22). Dans I do not know what it is I am like (1986), la table en bois dressée avec un verre à pied bordé d'or, une carafe en verre travaillé et à moitié pleine de vin blanc, un poisson cuisiné et servi dans un compotier en argent, un oignon blanc, un rouge, une gousse d'ail et un morceau de pain, un drapé sombre sur le fond (fig.23a) renvoient sans ambiguïté aux natures mortes baroques. Ce renvoi est cependant immédiatement subverti par la présence de B. Viola qui, assis à table, nettoie et mange le poisson, rompt le pain et boit le vin (fig.23b). Les séquences montrant les grenades mûres, ouvertes puis séchées (fig.23c), la bougie allumée qui se consume lentement ou les mouches qui se posent sur la carcasse d'un buffle en putréfaction (annonçant déjà Sweet Light) pourraient, elles aussi, être qualifiées de baroques.

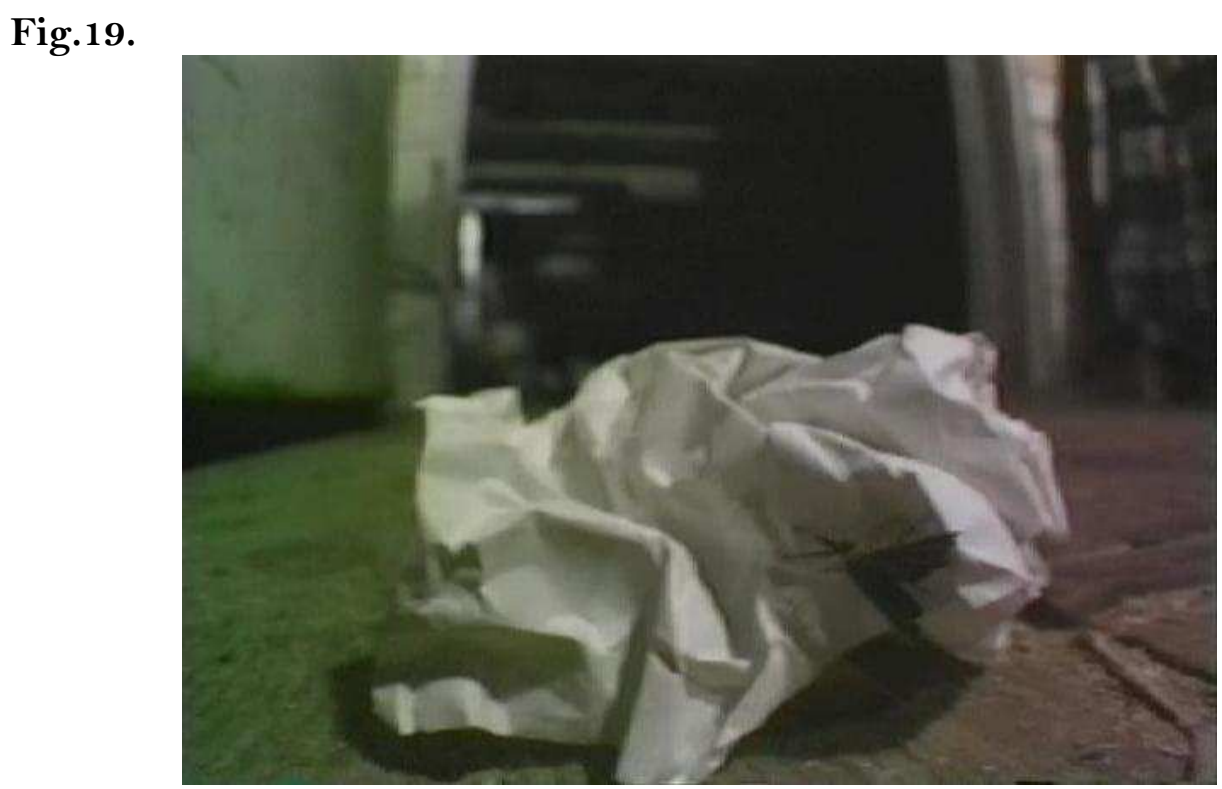

Bill Viola, Sweet Light, 1977 - photogramme

\footnotetext{
${ }^{12}$ Voir l'entretien filmé de M. Kidel, Bill Viola. The Eye of the Heart : a portrait of the artist, Paris, Calliope Media Production et Arte France, 2004.
} 
Fig.20.

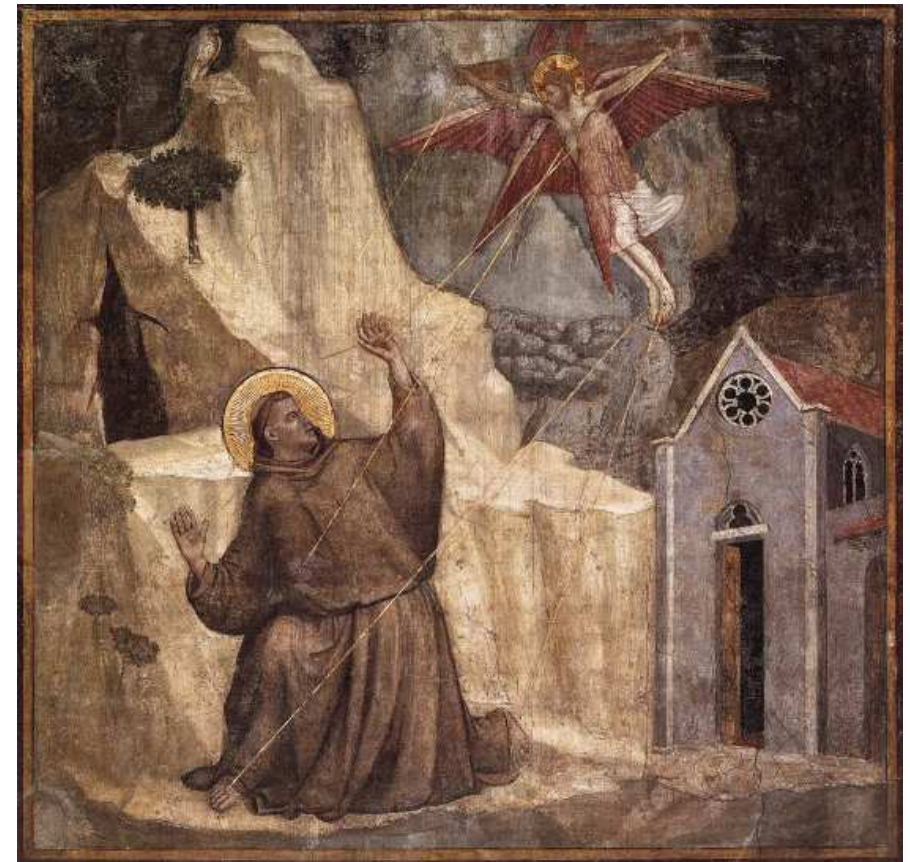

Giotto, La Stigmatisation de Saint François, 1297-1300.

Fresque, Assise, basilique supérieure de Saint François,

Fig.21a.

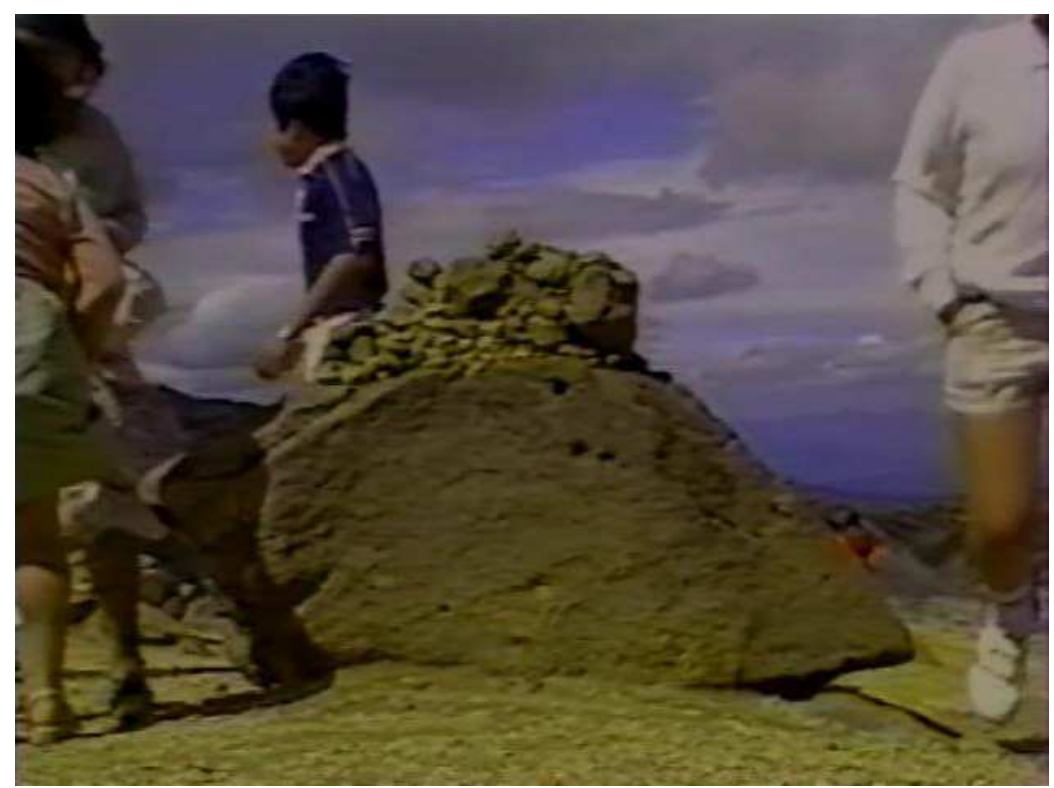

Bill Viola, Hatsu-Yume First Dream, 1981 - photogramme

in B. Viola (dir.), Hatsu-Yume First Dream, [1981] 2006, (dvd), Éditions À Voir, 56 mins 
Fig.21b.

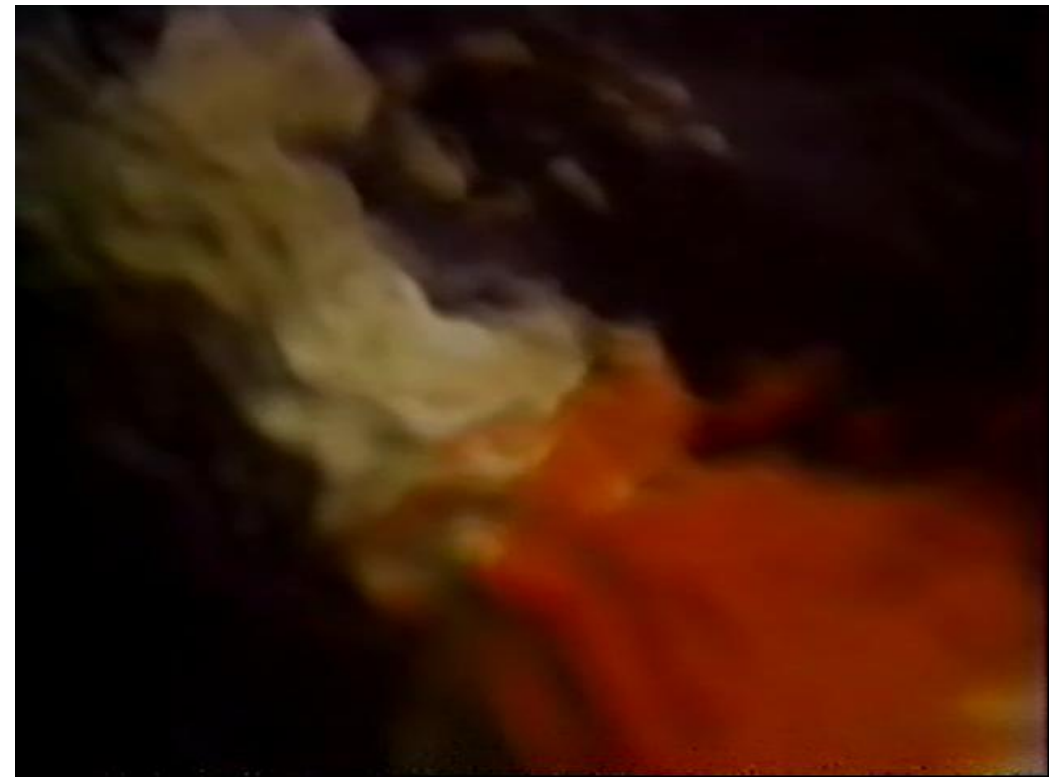

Bill Viola, Hatsu-Yume First Dream, 1981 - photogramme

in B. Viola, Hatsu-Yume First Dream, [1981] 2006, (dvd), Éditions À Voir, 56 mins

Fig.22.

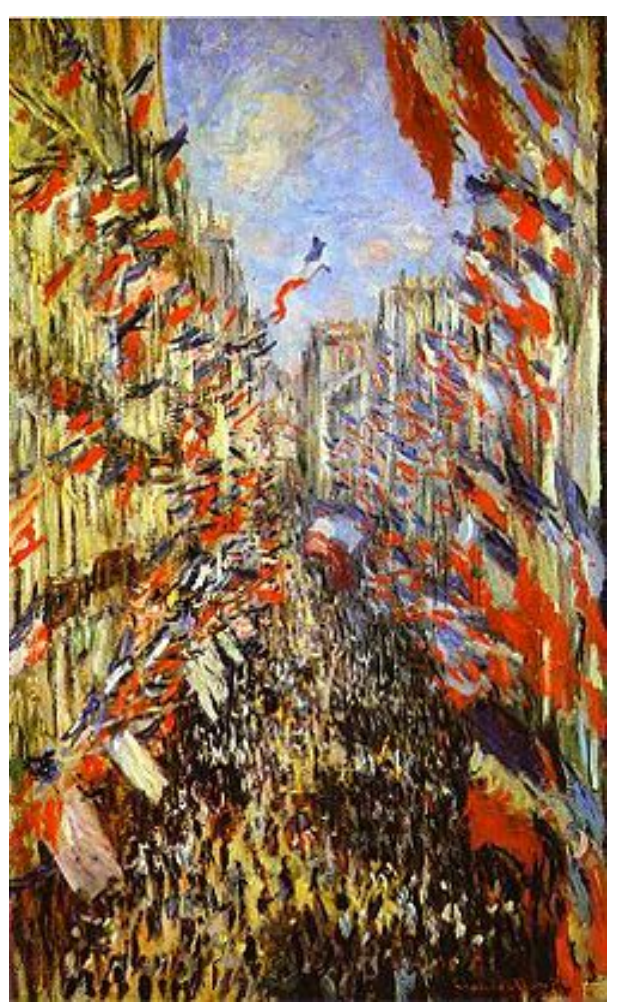

Claude Monet, La Rue Montorgueil à Paris. Fête du 30 juin 1878, 1878.

Huile sur toile, Paris, Musée d'Orsay 
Fig.23a.

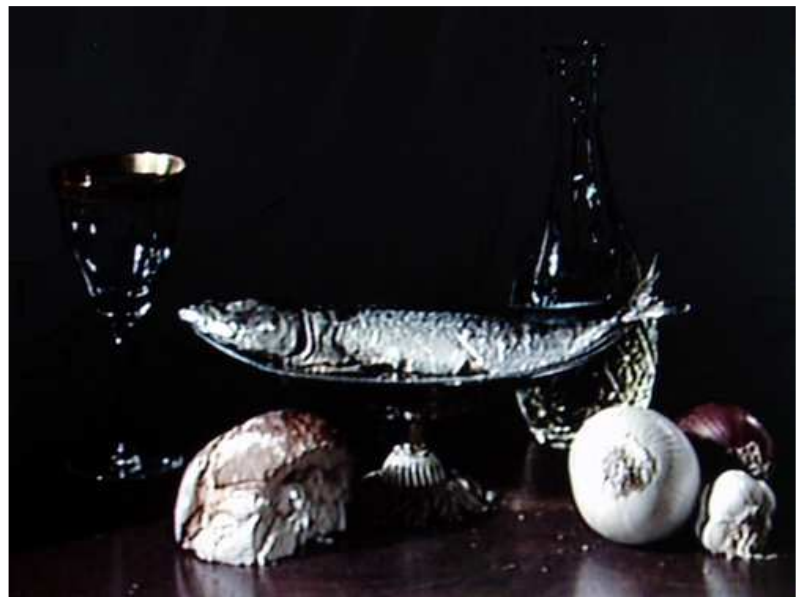

Bill Viola, I do not know what it is I am like, 1986 - photogramme

in B. Viola (dir.), I do not know what it is I am like, [1986] 2006, (dvd), Éditions À Voir, 89 mins

Fig.23b.

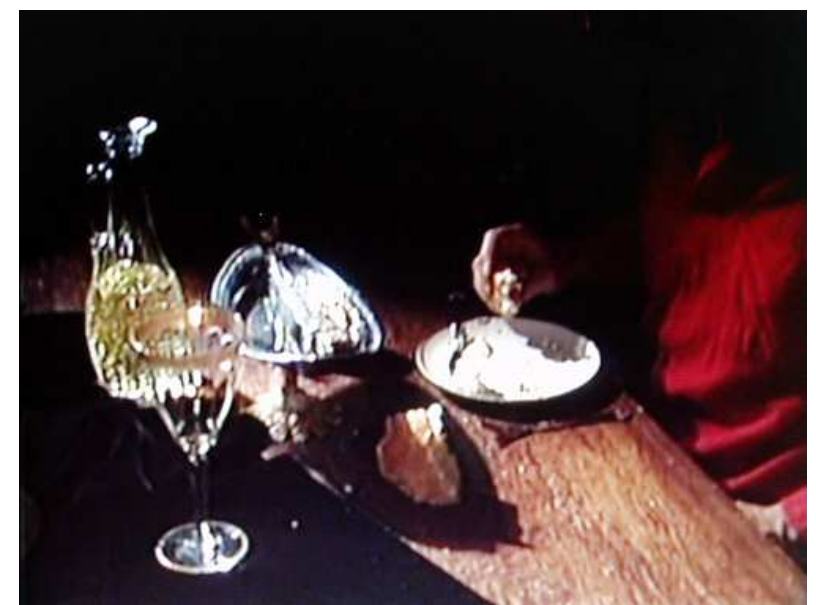

Bill Viola, I do not know what it is I am like, 1986 - photogramme

in B. Viola, I do not know what it is I am like, [1986] 2006, (dvd), Éditions À Voir, 89 mins

Fig.23c.

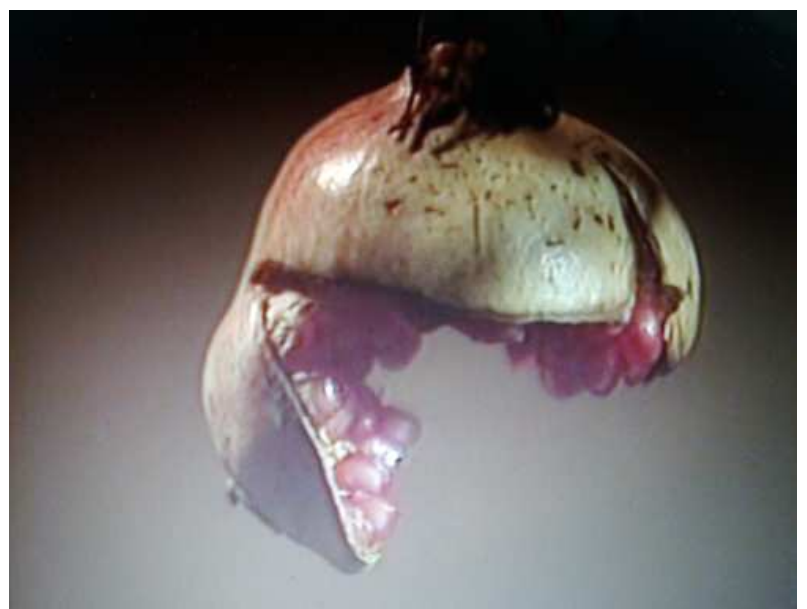

Bill Viola, I do not know what it is I am like, 1986 - photogramme

in B. Viola, I do not know what it is I am like, [1986] 2006, (dvd), Éditions À Voir, 89 mins 
Une telle récurrence de stylèmes figuratifs connus et partagés n'est cependant pas un indice fiable pour sonder la production de B. Viola, à moins de vouloir la disséquer comme s'il s'agissait d'un film dont on veut évaluer les photogrammes. De la même façon, la confiance que le spectateur accorde à des éléments figuratifs aussi vifs dans le cycle sur les passions a pour résultat d'en fausser la spécificité esthétique en le simplifiant et, d'une certaine manière, en le camouflant au sein du patrimoine de l'art pictural. Cela se produit en dépit du fait qu'il présente des images dont l'iconologie est beaucoup moins complexe et stratifiée que celle des premières productions, apparemment au profit d'une gestuelle théâtrale, faisant se dérouler sous nos yeux quelque chose de beaucoup plus proche d'une action pure, exécutée par des acteurs en costume qui interprètent des rôles.

\section{The Passions et la théâtralité}

B. Viola considère le théâtre comme «un art frère $»^{13}$ de la vidéo puisqu'il en partagerait la nature événementielle: dans le fonctionnement essentiel de l'apparat électronique, le temps de l'observation de la projection coïncide avec le temps de l'action filmée, tout comme le temps de réception coïncide avec le temps d'action de l'acteur. Pour la vidéo en effet, la durée, à l'analyse de laquelle B. Viola consacre une grande attention, est donnée par le temps d'activité de la caméra qui coïncide avec le temps réel de l'image, coïncidant à son tour avec le temps de perception du spectateur :

Dans le film, l'enregistrement est inséparable du médium. Dans la vidéo, il s'agit d'une étape secondaire. Pour avoir une vidéo, tu n'as pas besoin d'un appareillage pour enregistrer. Tu l'allumes et les circuits sont tous activés ; on entend le bourdon, il fonctionne. Il est plus en lien avec le son qu'avec le film ou la photographie, parce qu'il s'agit exactement de la même relation que celle existant entre microphone/caisse. [...] On peut dire que cette durée, ce toujours-là, est le temps réel ${ }^{14}$.

Il s'agit du mécanisme du système en circuit fermé - qui a joué un rôle important pour la naissance de l'art vidéo -, pour lequel celui qui regarde l'écran est filmé pendant qu'il l'observe depuis un moniteur qui lui renvoie sa propre image sans décalage temporel. Ce type d'analogie avec le théâtre s'avère cependant partielle dès lors que nous considérons la façon spécifique dont $\mathrm{B}$. Viola établit la réception de ses propres vidéos.

De toute évidence, le simple fait qu'il admette avoir été embarrassé en tant que réalisateur durant le tournage de The Passions lorsque les acteurs lui demandaient une justification dramaturgique expliquant les émotions qu'ils devaient manifester, révèle sa distance avec l'art du théâtre. Il n'éprouvait en effet aucune difficulté à diriger une vaste équipe composée de techniciens, costumiers, scénographes et maquilleurs, de nombreux figurants parfois, mais la nécessité de fournir une raison spécifique d'exprimer telle émotion plutôt qu'une autre était plus ardue à envisager. Ce qui l'intéresse en effet n'est pas le récit ${ }^{15}$, au point qu'une fois le script donné aux acteurs, il ne le considère pas comme une trame qu'ils peuvent partager donnant lieu à une action scénique cohérente, mais comme un manuel d'utilisation. La performer Weba Garretson, engagée pour The Quintet of Astonished, rappelle que le vidéaste travaillait singulièrement avec chacun des cinq acteurs, laissant chaque fois les quatre autres dans l'ignorance des instructions données au cinquième, et par

\footnotetext{
${ }^{13}$ B. Viola, «The sound of one line scanning » in D. Lender et M. Lexier (dir.), Sound by Artist, Toronto, Art Metropole, Banff, Walter Phillips Gallery, 1990, p. 39-54.

${ }_{14}$ R. Bellour et B. Viola, «An interview with Bill Viola », October vol. XXXIV, automne 1985, p. 91-119, ici p. 100. L'affirmation est de B. Viola.

${ }_{15}$ Voir J. Walsh, «Emotions in extreme time. Bill Viola's Passions project », art.cit., p. 31. La référence est à The Greetings.
} 
conséquent de l'action d'ensemble que le groupe était censé faire. Elle livre ainsi : "Pour un acteur, cette expérience était complètement antithéâtrale! Cinq d'entre nous se trouvaient dos à dos sans aucun contact visuel que ce soit... Nous n'avions d'autre choix qu'interagir physiquement $\gg^{16}$. C'était justement cette interaction involontaire de la singularité de chacun que B. Viola voulait voir et faire voir : «Pendant qu'ils bougent, tu saisis une configuration temporelle - "des constellations" et des moments culminants d'alignement qui se défont lorsque de nouveaux commencent à se former. Je suis intéressé par ce que les anciens maîtres n'ont pas peint, par les passages situés au milieu $\gg{ }^{17}$.

Fig.24.

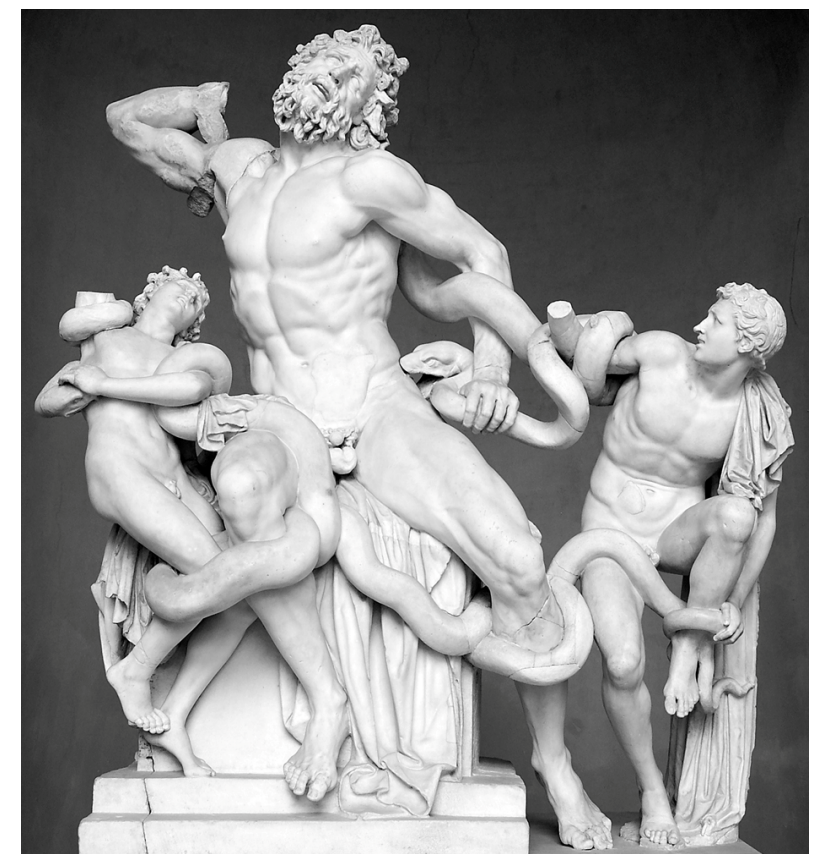

Agésandros, Polydoros et Athénodoros, Laocoon, c. 40 av. J.-C.

Rome, Musée du Vatican

Pourtant, ces passages invisibles des anciens maîtres (fig.24) sont ceux qui invitent le spectateur de l'art pictural et plastique à mener à son terme le mouvement pathique qui n'est qu'esquissé dans l'œuvre tout en le complétant par l'imagination. Il s'agit donc de ce qui relie l'expérience esthétique à l'activité intellectuelle, obligeant le spectateur à un engagement non seulement émotionnel mais recréatif et libre. B. Viola offre en revanche avec les ouvres du cycle une version essentiellement conservatrice du rôle des émotions dans l'expérience de la réception, aidé en cela par l'effet hypnotique du ralenti : un long cri ininterrompu est un cri impuissant qui ne fait que s'affirmer et se refermer sur lui-même. Aucune compétence particulière n'est demandée au spectateur, une fois que sa présence physique devant l'écran est avérée. C'est pourquoi je décrirai le mouvement des acteurs des vidéos du cycle, avec Erwin Straus, comme un «mouvement présentiel », qui est «non dirigé et non limité [...]; il enfle et décroit, s'élève et retombe. Il ne suscite aucune modification ; il n'est pas un procès historique. C'est précisément pour cette raison que nous le nommons présentiel - et ce à bon droit malgré sa durée dans le temps objectif ${ }^{18}$. B. Viola n'est effectivement pas intéressé par l'action, mais par le rythme séquentiel des gestes, pas par la représentation d'un événement, mais par l'exposition de sa durée ; il prête plus d'attention à l'effet histoire qu'à l'histoire elle-

${ }^{16}$ Ibid., p. 36.

17 Ibidem.

18 E. Straus, «Les formes du spatial», in J.-F. Courtine (dir.), Figures de la Subjectivité. Approches phénoménologiques et psychiatriques, (tr. de l'allemand par M. Gennart), Paris, éditions du CNRS, 1992, p. 15-49, ici p. 41. 
même, cet effet partant de la stimulation perceptive exercée sur les individus assistant au déroulement de la vidéo.

Cette simple mise en scène des corps qui ne se réfèrent pas à autre chose qu'à euxmêmes est incompatible avec le théâtre qui est un art de l'écart et de la différence contrastant avec une prétendue «immédiateté naturelle ». Le théâtre se construit grâce à la simultanéité de la présence et de l'absence réciproque de l'acteur et du spectateur, il est régi par le seuil de la fiction marqué par le cadre de la scène. Dans la vidéo, un tel seuil est supprimé. Nous avons le «devenir-image du personnage, le devenir-personnage de l'image ${ }^{19}$. Aucune résistance de la part du spectateur n’est donc possible, étant donné que :

si la vidéo est un médium, alors, l'une de ses propriétés matérielles pourrait être le corps : le corps comme sujet est en fait constitutif du médium de la vidéo elle-même. Ce n'est pas un hasard si la quasi-totalité de l'art vidéo à ses débuts tourne la caméra vers l'artiste, généralement dans l'intimité de son atelier ou lors de l'exécution d'une performance dans laquelle le corps de l'artiste devient le lieu ${ }^{20}$.

Au théâtre, le corps montré sur la scène est en revanche le masque que l'acteur obtient en métamorphosant son corps en vue de créer, dans cet écart, celui du personnage, évitant ainsi la deixis en vertu de quoi un bras est un bras, un cri est un cri.

Par conséquent, du point de vue formel, B. Viola est en définitive absolument antithéâtral. De plus, du point de vue du contenu - que nous distinguons momentanément de la forme pour les besoins du raisonnement -, si la qualité pathique des vidéos du cycle dépendait vraiment de la netteté du contour des visages et des corps qui mettent en scène la prétendue théâtralité d'une expression incarnée par un acteur l'exhibant devant nous, à une certaine distance de sécurité et dans les limites du cadre de l'écran, ces ouvres seraient des tableaux vivants mis à jour d'un point de vue technologique. Il deviendrait alors à nouveau nécessaire de formuler l'hypothèse d'une trame narrative aussi minime soit-elle, tout en sachant, comme nous l'avons vu, que B. Viola s'en désintéresse.

Cynthia Freeland propose une hypothèse de travail allant dans ce sens quand elle écrit à propos de The Passions que «le réalisme des émotions que nous voyons dans les vidéos nous oblige à imaginer une insupportable source de douleur $\gg^{21}$, comme étant la cause des expressions troublées des visages que B. Viola a filmés. Cependant, imaginer la cause revient à attribuer à la vidéo la fonction d'un documentaire pathique qui annoncerait le thème de la représentation mise en scène, malgré le fait que la raison effective de l'histoire soit soustraite au regard. Il me semble que Viviana Gravano défend implicitement elle aussi la même interprétation quand elle remarque, à propos de The Quintet of Astonished:

Ce qui dérange $[\ldots]$ cette image jusqu'à provoquer la commotion, ce n'est pas seulement la vision du désespoir montrée dans ses moindres détails, sans voiles, grâce au ralenti, mais c'est notre complète identification à la fois avec les personnes en deuil qu'avec le corps du mourant. Il s'agit donc du partage d'un espace commun qui nous permet de faire face à la douleur et à l'objet du chagrin à partir du même point de vue que les endeuillés. [...] Notre regard affronte la douleur des autres mais, grâce à une projection émotionnelle naturelle, demande à voir la source qui cause tant de douleur ${ }^{22}$.

\footnotetext{
19 J.-P. Fargier, « The reflecting pool de Bill Viola », Crisnée (Belgique), Yellow Now, 2005, p. 12.

20 J. Lahey Dronsfeld, «On the anticipation of responsibility », in C. Townsend (éd.), The Art of Bill Viola, Londres, Thames \& Hudson, 2004, p. 72-88, ici p. 77.

21 C. Freeland, «Piercing to our inaccessible, inmost Parts. The Sublime in the work of Bill Viola», in C. Townsend (éd.), The Art of Bill Viola, op.cit., p. 24-46, ici p. 34.

${ }^{22}$ V. Gravano, «L'immagine come traduttore : dalla memoria condivisa alla memoria intima », in Art'O. Cultura e politica delle arti sceniche 26, automne 2008, p. 32-41, ici p. 39.
} 
Une telle position maintient évidemment le pouvoir poïétique de l'image, mais continue de la lire dans la logique du contenu émotionnel, dont le résultat, à mon avis, est de passer à côté de la puissance spécifique des vidéos de B. Viola.

S'il est vrai que ce qui frappe dans les ouvres du cycle est le réalisme optique qui caractérise à chaque instant les corps presque taillés dans l'écran, comme s'il s'agissait de portraits naturalistes, une telle ligne de recherche ne répond cependant pas aux questions esthétiques que les auvres soulèvent, mais les intègre plutôt dans une mise à jour iconographique de postures qui ne peuvent qu'apparaître, selon Jonathan Lahey Dronsfeld, comme des «réponses imposées, littérales, illustratives, dogmatiques, pour lesquelles le spectateur ne peut qu'accorder son consentement $»^{23}$. Si nous acceptons ce principe, alors oui, « la force d'une image, pour B. Viola, résidera toujours dans son contenu de représentation $»^{24}$. Si nous développions cette position jusqu'à ses conséquences ultimes, nous devrions ajouter que ces images, telles qu'elles se présentent, sans la moindre ironie, seraient de nature purement spectaculaire ${ }^{25}$. Le lien entre la puissance de ces images et leur contenu pathique ne découle cependant pas de raisons d'ordre thématique, qui conduiraient à placer le travail de B. Viola dans la catégorie du sublime ${ }^{26}$.

Ce qui survient dans The Passions est plutôt une reformulation d'expressions émotionnelles qui, libérées de la fixité de l'image bidimensionnelle, suggèrent une sorte de déroulement, une chaîne d'états d'âme sans développement narratif : l'histoire est absorbée dans la - prétendue - universalité de l'émotion. Le contexte produirait, selon B. Viola, un élément artificiel, c'est ce qui l'a incité à « supprimer le script, la narration, et n'avoir affaire qu'aux émotions ». Il ajoute : «Je suppose que c'est la même chose pour un peintre, dans un sens, qui veut accéder au rouge en tant qu'expérience ou couleur pure, et non comme la part d'illusion picturale d'une rose ${ }^{27}$. Ce qui l'intéresse, c'est donc de travailler sur la forme pure de l'expression des émotions, qu'il ramène à quatre émotions primaires - joie, tristesse, peur, colère - et traite comme s'il s'agissait des quatre couleurs primaires ${ }^{28}$. Hans Belting remarque avec raison la façon dont les émotions sont pour B. Viola comme « une sorte de situation contrôlée en laboratoire pour enquêter sur le visage et l'image ${ }^{29}$. J. Walsh a par ailleurs écrit : «Avec The Passions, il explore les émotions comme s'il s'agissait de quelque chose pouvant être comparé à la "vision pure" : des états élémentaires de sentiment sans antécédent ou justification apparente. Il teste plusieurs instruments, afin de permettre aux spectateurs de faire l'expérience des passions sous une forme purifiée $\gg^{30}$.

Une comparaison entre la peinture et le théâtre peut justement montrer par contraste que le travail de B. Viola a une autonomie esthétique spécifique qui, comme nous le verrons, le place dans une position antithétique face à ces deux arts qui pratiquent une économie précise de la fiction. Cette autonomie se fonde sur l'élision préalable du seuil de la fiction qui fait la distinction entre la réalité et sa simulation et permet de marquer la différence entre la

\footnotetext{
23 J. Lahey Dronsfeld, «On the anticipation of responsability», art.cit., p. 76. Pour une critique de la «banalité » dans le travail de Bill Viola, voir C. Keith, "Image after image : The video art of Bill Viola », $A$ Journal of Performance and Art vol. XX, no 2, mai 1998, p. 1-16.

${ }^{24}$ J. Lahey Dronsfeld, « On the anticipation of responsibility », art.cit., p. 79.

25 Je partage le jugement d'Anne M. Wagner dans ce sens, pour qui «ce qu'il manque aux méditations spectaculaires sur la vie, la mort et la transcendance de Viola, c'est une forme de défiance construite à l'intérieur de son propre médium. Même l'ironie ne peut mettre son message entre parenthèses. Au contraire, son travail prétend - parfois au point de devenir coercitif $[\ldots]$ - nous faire croire à la grandeur et à la richesse de sens de ce que la vidéo et l'artiste nous donnent à voir» («Performance, video, and the rhetoric of presence », October vol. XCI [hiver, 2000], p. 59-80, ici p. 80).

${ }^{26}$ Sur le sublime chez B. Viola voir C. Freeland, «Piercing to our inaccessible, inmost Parts. The Sublime in the work of Bill Viola », art.cit.

27 «A conversation. Hans Belting and Bill Viola », 28 juin 2002, in Bill Viola. The Passions, op.cit., p. 189-220, ici p. 201.

${ }_{28}$ Ibid., p. 200.

${ }^{29}$ Ibid., p. 202.

so J. Walsh, « Emotions in extreme time. Bill Viola’s Passions project », art.cit., p. 61.
} 
vie vécue et la réception esthétique. Son travail révèle une nature afictionnelle. $\mathrm{B}$. Viola aboutit ainsi au résultat paradoxal de produire une «image sans représentation» qui permet, par la mise en avant de l'expressivité originaire de l'homme, de produire un effet émotionnel persuasif, affirmatif même, sur le spectateur.

\section{De la fiction à la contamination}

Pour saisir cette nature afictionnelle, il faut comparer la construction dramatique et le mécanisme de la représentation du court-métrage Film (1964) de Samuel Beckett et I don't know what it is I am like. Dans Film, le personnage principal, joué par Buster Keaton, toujours filmé de dos jusqu'à la séquence finale, a le visage couvert d'un mouchoir afin d'éviter les regards des passants qu'il croise et dont le spectateur voit les réactions de désarroi, comprenant par leur intermédiaire que l'aspect de B. Keaton est particulièrement inquiétant. Arrivé enfin dans sa chambre, il enlève son mouchoir et regarde prudemment autour de lui avant d'accomplir les actions suivantes: il tire le sombre rideau (cruellement et ironiquement lacéré), marche en rasant les murs, couvre d'un drap noir le miroir afin de ne pas se voir, chasse un chiot et un chaton qui le regardent, arrache un dessin accroché au mur représentant un masque avec deux énormes yeux et le déchire, remarque la présence d'un perroquet (dont l'œeil droit est cadré avec insistance) et couvre la cage avec son manteau ; enfin, l'œil d'un poisson dans un bocal en verre occupe le centre du plan et B. Keaton se précipite pour le cacher sous un pan de vêtement. La pièce enfin aveugle, il regarde des photographies de lui-même et des siens et les déchire pour être finalement accablé par sa propre image - monocle - qui le fixe par le seul œil ouvert (fig.25). La question centrale de Film est le mécanisme de la réflexion, non la simple relation spéculaire à l'origine du processus de représentation de soi qui surgit de l'inévitable expérience qui consiste à être observé : nous nous reflétons dans les yeux de l'autre qui nous renvoie une image de nousmêmes, laquelle ne nous appartient pas précisément parce qu'elle est image.

Fig.25.
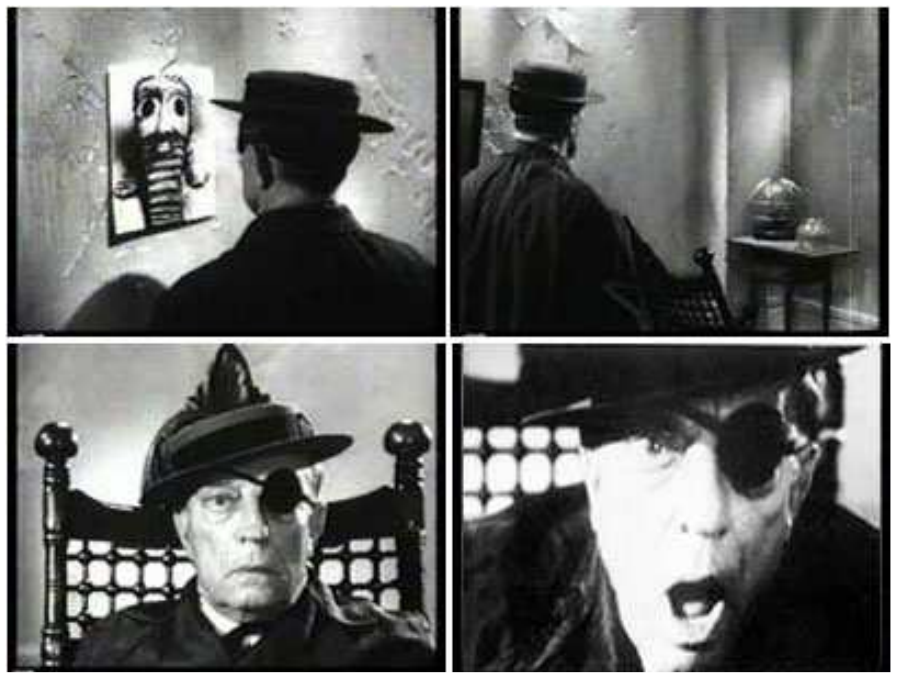

Samuel Beckett, Film, 1964

Comparons maintenant le court-métrage de $\mathrm{S}$. Beckett avec la séquence que B. Viola consacre à l'œil dans sa vidéo de 1986 : nous saisissons une profonde différence de poétique significative de la différence entre les deux médias. Le vidéaste monte une succession de plans montrant des animaux dont il choisit de présenter en particulier l'œil : un bison, deux 
poissons, quatre grands oiseaux, un petit duc. L'œil en effet - ouvert, fermé, coupé - est présent dans toutes les vidéos précédant celles du cycle The Passions, mais dans celle-ci, elle a un rôle plus paradigmatique, au point que B. Viola a déclaré dans un entretien accordé des années plus tard à Mark Kidel que le thème était alors celui de l'incapacité caractéristique de la vie contemporaine, non pas tant de faire preuve d'empathie, mais plutôt de "se réfléchir en l'autre », et de «devenir [ainsi] un autre être ${ }^{31}$. B. Viola avait déjà précisé ce qu'est pour lui ce mécanisme de réflexion :

Le miroir idéal, dès le début de l'humanité, a été le fond noir de la pupille. Il $\mathrm{y}$ a une propension naturelle de l'homme à vouloir regarder fixement dans les yeux d'un autre, ou, par extension de soi-même, un désir de voir la vision elle-même, comme si l'effort pour regarder à l'intérieur du petit centre noir de l'œil pouvait révéler non seulement les secrets de l'autre, mais la totalité de la vision humaine. Après tout, la pupille est la limite et le voile entre la vision intérieure et extérieure. En regardant attentivement dans les yeux, la première chose, voire la seule, que l'on voit, c'est sa propre image. Cela nous rend conscients du fait que l'acte de fixer une pupille possède deux propriétés inhabituelles : la première est la condition d'une réflexion infinie, le premier feedback visuel. Même la personne minuscule que je vois à l'arrière-plan de la pupille a un oeil dans lequel se reflète la très petite image d'une [autre] personne... et ainsi de suite. La seconde est l'élément physique faisant en sorte que de près, je parviens à avoir une meilleure vision dans l'œil, mais dans ce cas, ma propre image devient plus large et obstrue la vue ${ }^{32}$.

Ce dont parle le vidéaste n'est cependant pas de la réflexion de deux figures, mais de la compénétration de deux sources de vision. Cette séquence montre la contamination de son propre corps avec un corps animal, qui survient alors que son apparence se diffuse progressivement dans la pupille des différents oiseaux qu'il observe, jusqu'au point culminant atteint avec le petit duc. B. Viola serre en effet le cadrage sur les yeux du rapace pour ne sélectionner que l'oil droit et zoomer sur la pupille noire entourée d'un iris jaune (fig.23d). Nous y distinguons alors l'image du corps du vidéaste : il est vêtu d'un costume sombre, agenouillé par terre à côté du trépied de la caméra, le casque sur la tête, il se déplace, derrière lui se trouvent des arbres, l'environnement naturel de l'oiseau (fig.23e). Immédiatement après, B. Viola vêtu d'un pull à col roulé blanc qui se détache sur le noir, entre dans la pupille alors qu'il avance vers le trépied, pour se retrouver enfin dans une pièce où une lumière artificielle, située à sa gauche, en hauteur, projette son ombre sur le mur du fond à sa droite (fig.23f). À chaque moment, les regards de B. Viola et de l'oiseau ne se répondent pas et ne s'évitent pas non plus, ils sont à l'arrêt, n'interrogent pas, ne prévoient pas, n'anticipent pas, ne se déplacent pas. Le corps de B. Viola plonge dans son propre reflet comme s'il tombait dans l'eau pour s'être penché un peu trop. La même chose se produit dans la séquence qui suit où l'on voit la flamme d'une bougie se consumer dans la pupille de B. Viola assis à sa table de travail (fig.23g).

\footnotetext{
${ }^{31}$ Voir l'entretien accordé à M. Kidel, Bill Viola. The Eye of the Heart: a portrait of the artist, op.cit..

${ }^{32}$ B. Viola, «Video Black - The mortality of the image », in D. Hall et S. Jo Fifer (dir.), Illuminating Video. An essential guide to video art, New York, Aperture Found, 1990, p. 477-486, 520.
} 
Fig.23d.

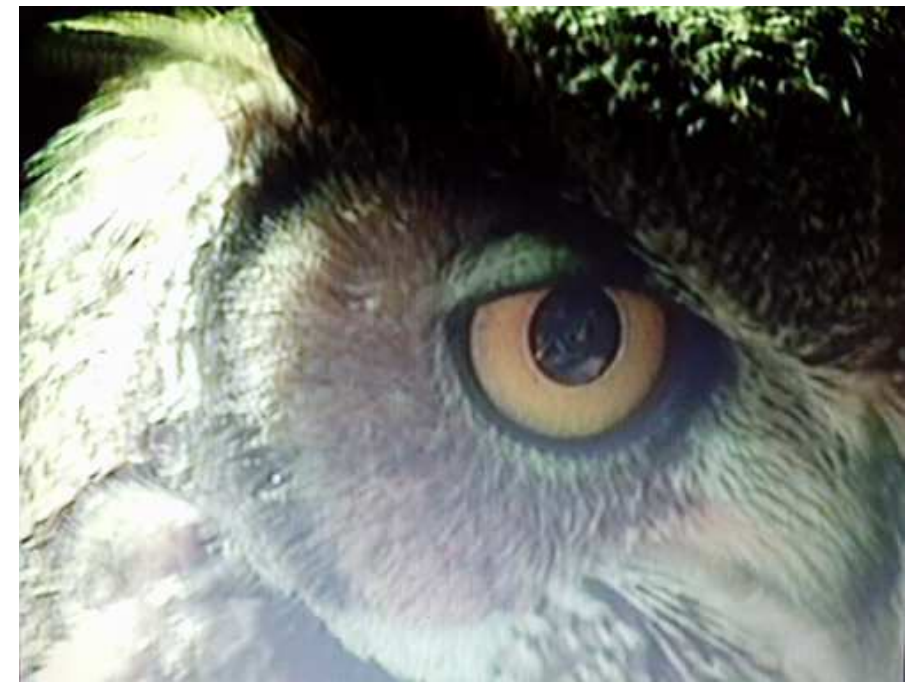

Bill Viola, I do not know what it is I am like, 1986 - photogramme

Fig.23e.

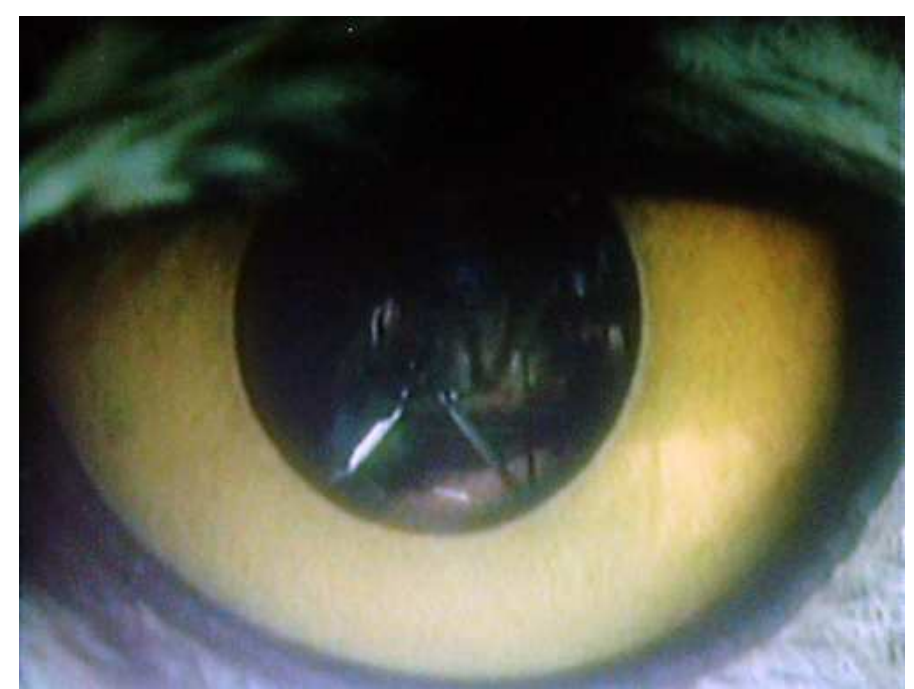

Bill Viola, I do not know what it is I am like, 1986 - photogramme

Fig.23f.

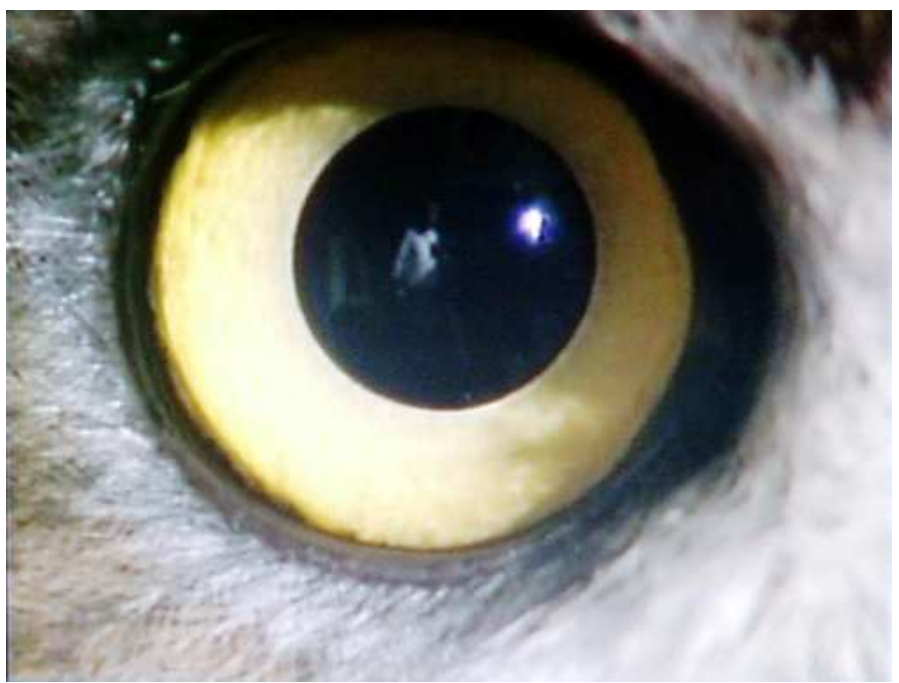

Bill Viola, I do not know what it is I am like, 1986 - photogramme 
Fig.23g.

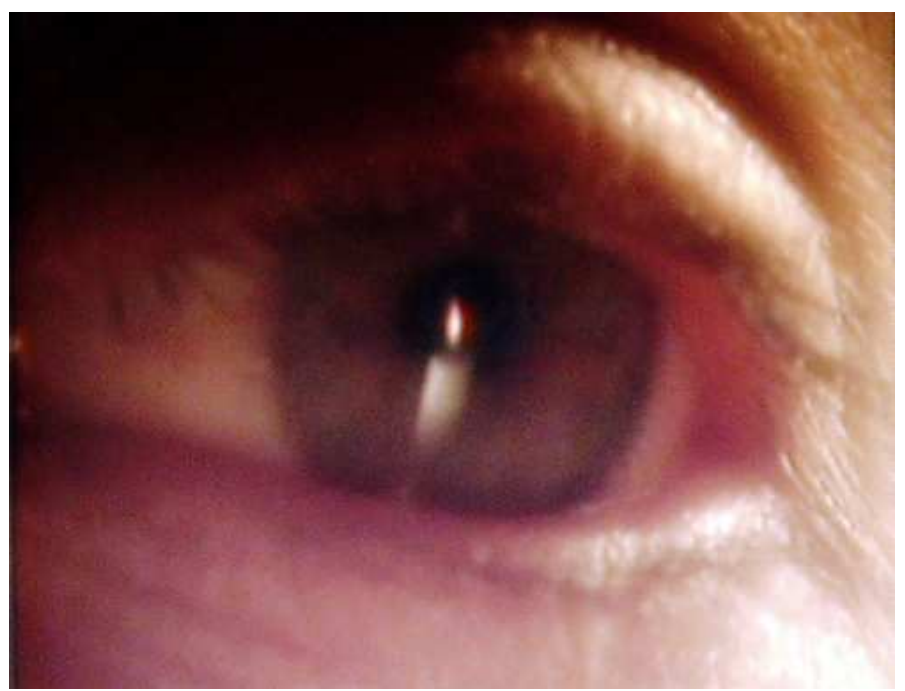

Bill Viola, I do not know what it is I am like, 1986 - photogramme

Figs.23 in B. Viola, I do not know what it is I am like, [1986] 2006, (dvd), Éditions À Voir, 89 mins

Fig.26.

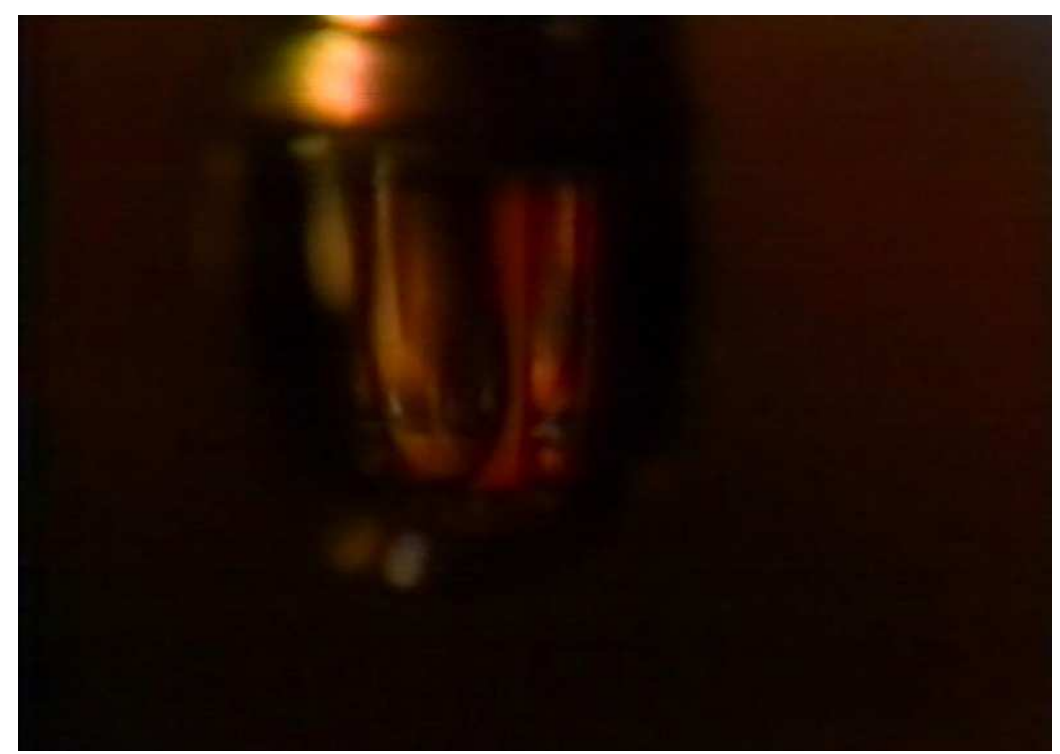

Bill Viola, Migration, 1976 - photogramme

in B. Viola, Selected Works, 2010, (dvd), Éditions À Voir, 54 mins

Cette « réflexion » est plus proche de l'inclusion d'un corps dans sa propre image que de la duplication d'une image dans le miroir, comme nous pouvons également le remarquer dans Migration (1976), où le visage de B. Viola se déforme dans les gouttes d'eau - dont il prend la forme - qui tombent à un rythme régulier coulant devant lui dans une bassine (fig.26), ou encore dans le verre d'eau ${ }^{33}$ appuyé sur la table de travail dans I do not know it is I am like. Il en résulte une compréhension de l'image qui n'est par conséquent ni évidente, ni au contraire douteuse. Nous n'avons ni la transparence du miroir, ni le doute sur le statut de

\footnotetext{
${ }^{33}$ Le verre d'eau est un objet récurrent dans les vidéos de B. Viola, comme le morceau de pain, les céréales
} Kellogg's, les biscottes Quaker Oats, les bougies, les lampes de bureau... 
cette apparence que nous reconnaissons devant nous. Il s'agit d'une perfusion qui, dissolvant l'altérité des corps, ne peut solliciter une projection de la part du spectateur, à savoir une transposition empathique grâce à laquelle il atteste la présence de l'image et fait l'expérience de l'émotion qu'elle lui procure. En outre, le spectateur se retrouve dépossédé de sa propre individualité, se faisant, il ne demande pas à voir l'origine de l'action parce qu'il ne sait pas ou regarder, il ne sait pas reconnaître son propre point de vue ou trouver le début de la scène observée.

The Passions semble donc confirmer l'axe de recherche antérieur à l'année 2000. En effet, B. Viola affirmait déjà clairement en 1984 que ce qui l'intéressait n'était absolument pas la «simulation d'une situation », comme cela se produit précisément dans les films, mais plutôt la construction d'une narration qui s'adresse au système nerveux puisque «la structure narrative fait partie de notre système nerveux $\gg^{34}$. Lorsqu'il commente le cycle il rend d'ailleurs compte de la fixité du cadrage en disant que s'il avait bougé la caméra, l'émotion qui aurait surgi immédiatement après ce changement de cadrage aurait été détruite parce que l'expression de l'émotion qui vient à notre rencontre n'est autre que l'expression de la «continuité d'une vague d'émotion» qui est rendue visible à travers le corps d'une personne $»^{35}$.

Tout en tenant compte des évolutions techniques, il me semble donc qu'à partir des premières vidéos des années 1970 jusqu'au cycle The Passions, le même problème d'ordre esthétique - et politique - est à l'œuvre dans le travail de B. Viola. Il s'agit du délitement de l'identité psychologique du spectateur dans sa singularité. Comme l'a par ailleurs remarqué J.-P. Fargier, les différences entre les travaux des deux périodes témoignent non pas d'un changement de nature, mais du passage de la construction esthétique au sens propre de l'art de la vidéo à la déclaration d'une poétique sur l'art de la vidéo ${ }^{36}$. Comment B. Viola a-t-il pu conduire son spectateur vers une telle dissolution de soi-même indépendamment du degré d'immédiateté de présence iconique et de définition optique des images ?

La précieuse analyse de Rosalind Krauss permet de proposer une réponse. En 1976, elle affirmait dans Video: The Aesthetics of Narcissism, que le narcissisme ${ }^{37}$ est tellement endémique dans l'art vidéo qu'elle le considérait comme «la condition du genre dans son ensemble $»^{38}$. Alors que la peinture et la sculpture ne peuvent échapper aux conditions matérielles de leur médium qui oppose une certaine résistance à l'intention créatrice de l'artiste, le médium de la vidéo est la relation psychologique qui s'instaure entre l'image vidéo et le spectateur : la psyché humaine est le canal de l'art de la vidéo et le corps en est l'instrument ${ }^{39}$. La simultanéité presque parfaite entre le processus technique du tournage et la projection de l'image sur l'écran construit un «présent affaissé, c'est-à-dire un temps présent qui est complètement distinct du sentiment d'avoir un passé $»^{40}$. Dans ce présent, le corps du performer constitue son propre arrière-plan. Contrairement aux autres formes d'art qui créent une dissymétrie entre l'artiste et le spectateur, dénonçant la différence de positions existentielles et le rôle que chacun détient par rapport à l'œuvre - et que l'on pourrait appeler la différence de la fiction, bien que ce terme ne soit pas utilisé par R. Krauss -, la vidéo quant à elle, met en acte une symétrie entre les deux. L'analyse de R. Krauss concerne Centers de Vito Acconci, qui pointe son index au centre de l'écran produisant ainsi une relation tautologique avec le spectateur (fig.27). L'élément objectal de l'art vidéo, à

\footnotetext{
${ }^{34}$ R. Bellour et B. Viola, «An interview with Bill Viola », art.cit., p. 104. L'affirmation est de B. Viola.

${ }^{35}$ Voir l'entretien accordé à M. Kidel, Bill Viola. The Eye of the Heart : a portrait of the artist, op.cit.

${ }^{36}$ Voir J.-P. Fargier, « The reflecting pool de Bill Viola », art.cit., p. 95.

37 Définition donnée par Freud, selon laquelle la libido serait retirée de l'objet extérieur et réinvestit dans le moi du sujet. Voir S. Freud, «Pour introduire le narcissisme (1914)», in J. Laplanche (dir.), QEuvres Complètes (1913-1914), Paris, Presses Universitaires de France, 2005, vol. XII, p. 213-245.

${ }^{38}$ R. Krauss, «Video : The aesthetics of narcissism », October vol. I, printemps 1976, p. 50-64, ici p. 50.

${ }^{39}$ Le corps du performer dans l'enregistrement de la vidéo et le corps du spectateur dans les installations vidéo.

${ }^{40}$ R. Krauss, «Video : The aesthetics of narcissism », art.cit., p. 53.
} 
savoir son instrumentalisation électronique matérielle, est alors mis entre parenthèses. De cette manière « la conscience de la temporalité et celle de la séparation entre sujet et objet sont simultanément submergées. Le résultat de cette submersion est, pour celui qui fait et celui qui regarde la plupart de l'art vidéo, une sorte de chute sans poids à travers l'espace suspendu du narcissisme $»^{41}$.

Fig.27.

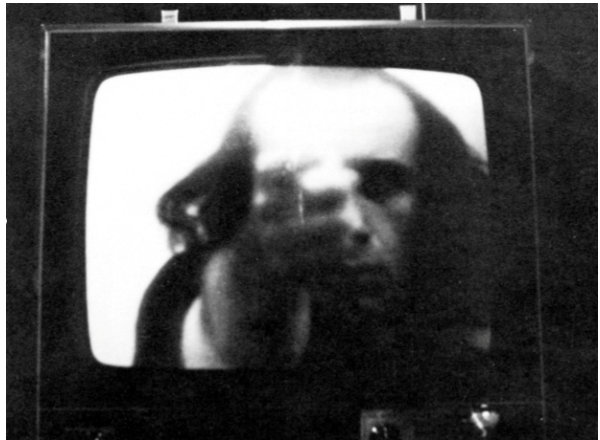

Vito Acconci, Centers, 1971

R. Krauss ne citait pas B. Viola, mais sa thèse s'applique assez bien au travail du vidéaste, tout comme nous montrent la résiliation du mécanisme de la réflexion mis en évidence par contraste avec le court-métrage de S. Beckett et le jeu de transfusion des sources de la vision dans la séquence déjà citée de I do not know what it is I am like. Mais ce seront les vidéos du cycle qui nous donneront la confirmation décisive. Là, le spectateur n’a d'autre choix que de se laisser engloutir par la fuite des émotions qui sollicitent son système nerveux sans pouvoir prendre la position d'un interlocuteur. Dans son excitation émotionnelle, il devient le personnage principal absolu de l'effet histoire. Nous assistons ainsi au développement de l'opération de V. Acconci: le passage du narcissisme à l'autoabsorbement ${ }^{42}$. Je fais référence en particulier à Observance où les acteurs regardent au loin indiquant ainsi que l'occasion émotionnelle de leur action se situe au-delà de l'espace délimité par l'écran, là où le spectateur pourrait se trouver, ils dépassent pourtant la position qu'il a effectivement, visant très clairement ainsi à ne pas l'interpeller (fig.28). Dans The Quintet of Astonished, les acteurs ne regardent pas en dehors du cadre, mais multiplient les points d'observation pour obtenir le même résultat: le spectateur est à la fois sollicité et refoulé. Dans Reverse Television - Portraits of Viewers (1983-1984) d'autre part, B. Viola mettait en acte un exercice d'observation apparent, sans pour autant que le regard de la personne filmée dans son salon, immobile devant la caméra, ne fut effectivement adressé au spectateur (fig.29). Ce n'est pas un hasard non plus si ces vidéos étaient destinées à la télévision, à être vues par des spectateurs qui pouvaient se trouver n'importe où. Il est certain que dans le cycle, ce sont les acteurs et non le performer qui «ne nous regardent pas », mais il s'agit d'une différence de poétique justement. Il n'en demeure pas moins que le regard des acteurs, dirigé hors des limites de l'écran, séduit le spectateur, l'entrave émotionnellement et provoque son solipsisme.

\footnotetext{
${ }^{41}$ Ibid., p. 59.

42 Anne M. Wagner, «Performance, video, and the rhetoric of presence », art.cit., p. 79. Voir M. Fried, Absorption and Theatricality: Painting and beholder in the age of Diderot, Berkeley - Los Angeles - Londres, University of California Press, 1980.
} 
Fig.28.

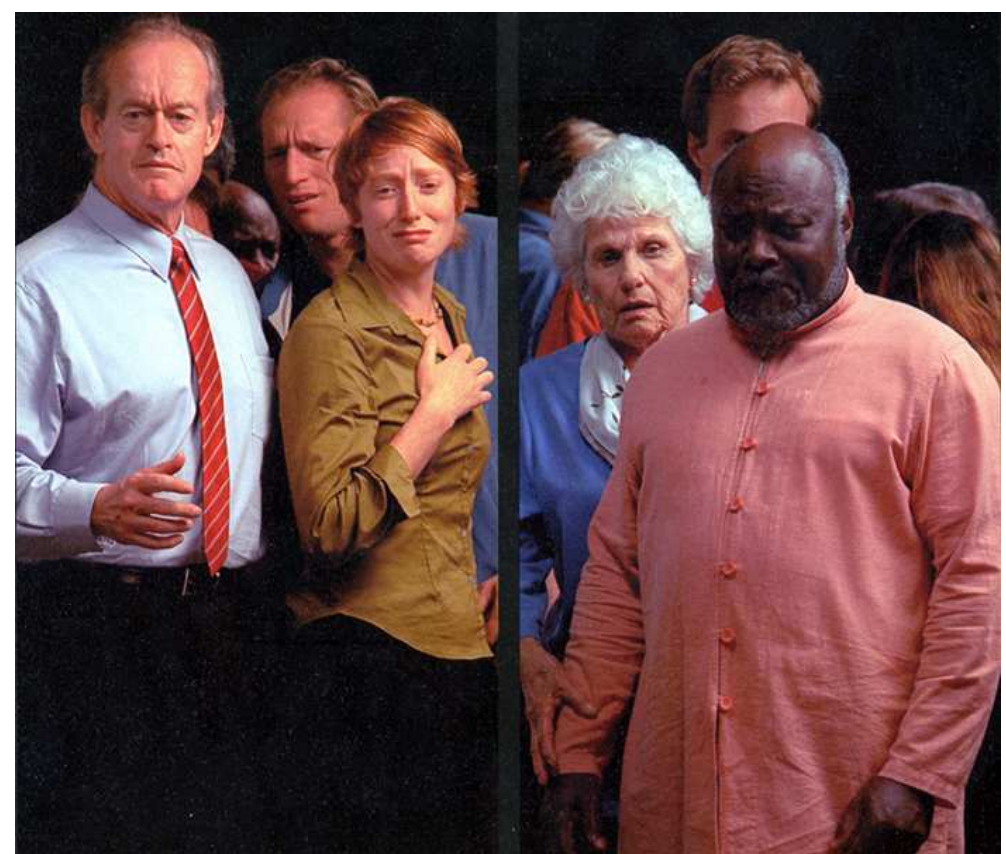

Bill Viola, Observance, 2002

in K. Perov, Bill Viola. Visioni Interiori, op.cit., p. 111

Fig.29.

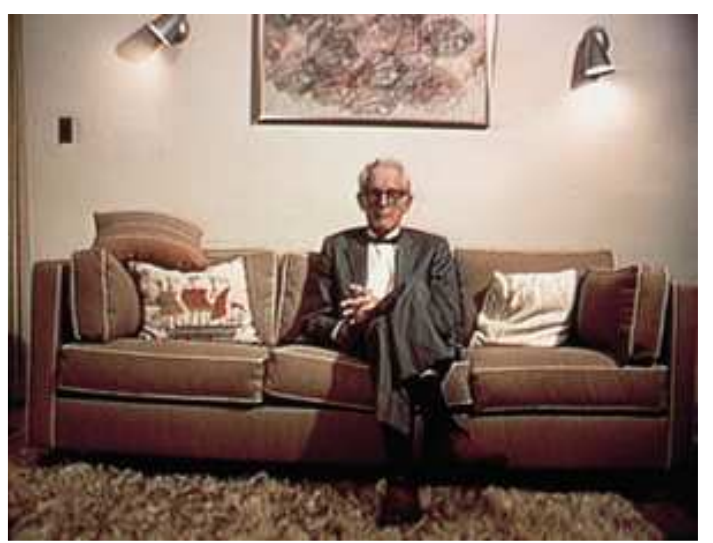

Bill Viola, Reverse Television - Portraits of Viewers, 1983-1984

De toute évidence, le mécanisme narcissique s'oppose au mouvement projectif d'empathie susmentionné. Il semble par conséquent confirmer l'axe de notre interprétation. Nous pouvons cependant aller plus loin. Arrêtons-nous un instant sur la scénographie du mythe ovidien racontant l'histoire d'un jeune homme se penchant sur une étendue d'eau et découvrant un beau visage masculin qui n'est autre que le reflet de lui-même, mais cela, Narcisse l'ignore. B. Viola a raison lorsqu'il affirme que «l'une des choses dont il est important de se rendre compte dans l'histoire de Narcisse est que son problème n'est pas qu'il a vu son propre reflet, est qu'il n'a pas vu l'eau. C'est le point capital. L'eau est la clé ! ».43 L'eau en tant que seuil devient même la thématique du vidéaste dans Ocean without a Shore (2007), dans lequel des murs d'eau invisibles - projetés pour apparaître transparents sont inopinément brisés par des acteurs qui avancent vers le spectateur et qui sont filmés en noir et blanc jusqu'au moment où ils les ont dépassés tout en se mouillant (fig.30). Ce faisant, ils manifestent l'existence de ces surfaces: l'image passe alors en couleur. S.-I. Dufour

43 «A conversation. Hans Belting and Bill Viola », art.cit., p. 206-207. 
remarque que «c'est l'histoire même de la vidéo qui se trouve ici sublimée » ${ }^{44}$ dès lors que cette œuvre enregistre le passage de l'image analogique à l'image numérique : une caméra haute définition se superpose à une caméra de surveillance, enregistrant l'image en noir et blanc, antérieure de vingt cinq années. Nous pourrions trouver un jeu analogue dans Surrender (fig.31). Cependant, dans cette vidéo, comme dans la scène d'ouverture de $I$ do not know what it is I am like, il est évident que B. Viola ne voit pas l'eau non plus : il la pénètre. Narcisse tombe dans l'eau comme B. Viola dans la pupille.

Fig.30.

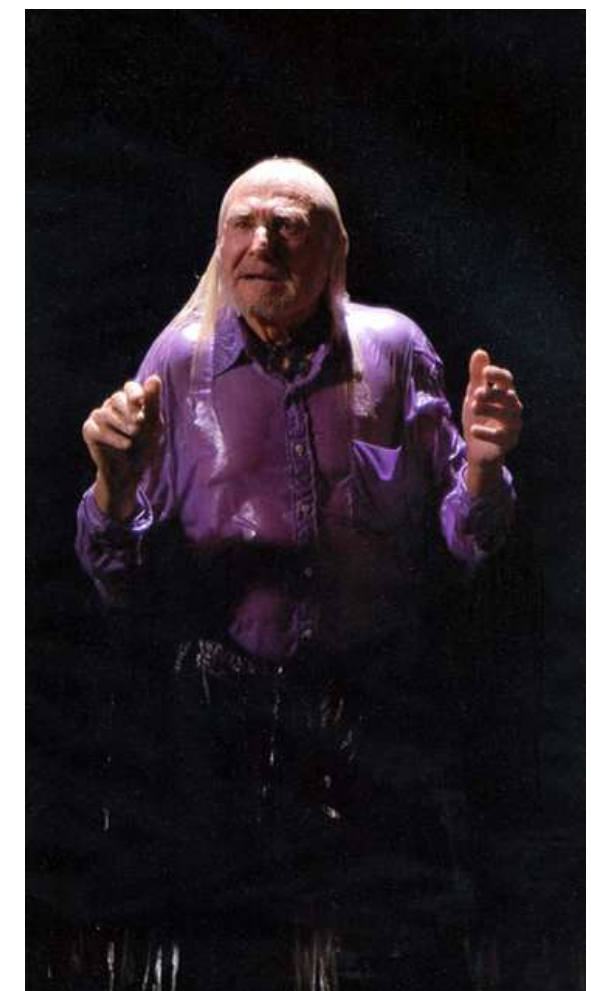

Bill Viola, Ocean without a Shore, 2007
Fig.31.

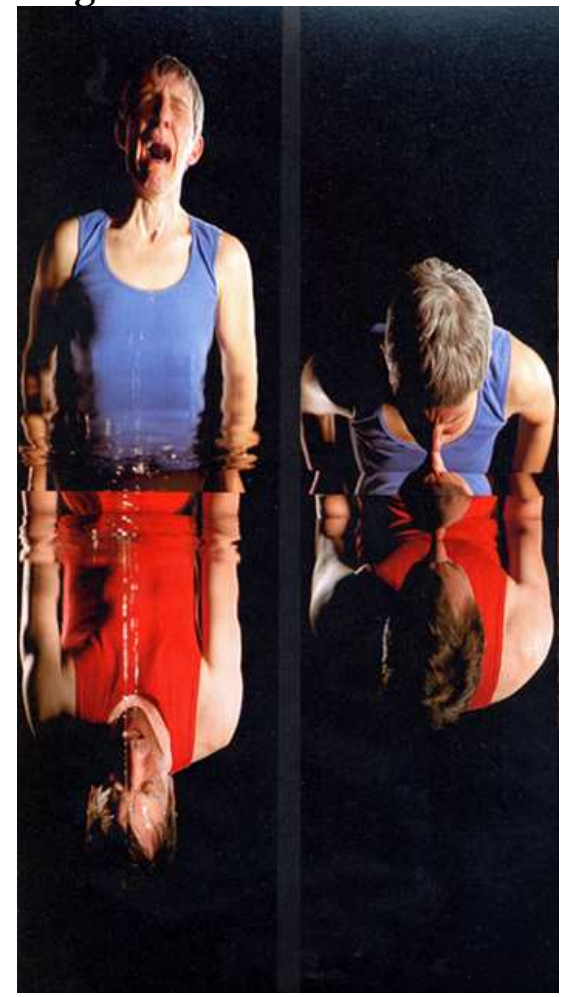

Bill Viola, Surrender, 2001

in K. Perov, Bill Viola. Visioni Interiori, op.cit., p. 123 et p. 78

Nous revenons ainsi à ce que nous évoquions plus haut sur l'antithéâtralité dans le travail de B. Viola et sur le rôle joué par la qualité de simple présence des corps exhibés sur l'écran du moniteur. La portée de ces deux aspects toutefois est ici amplifiée : le spectateur passe de l'observation de la représentation de l'expression d'une certaine expérience à la simulation de cette expérience coïncidant en lui avec sa propre expression, jusqu'à croire qu'elle lui appartient. Le caractère excitatif des vidéos de B. Viola et leur nature afictionnelle se justifient donc réciproquement. Le spectateur du cycle fait l'expérience directe sur luimême du véritable thème des vidéos qu'il observe : l'émotion. Celle du spectateur se confond avec l'émotion mise en scène rendant compte de l'instantanéité qui, comme on l'a dit au début, caractérise la réception du public de B. Viola que nous pouvons à présent mieux définir comme réactive. Il me semble par conséquent qu'il faut prendre au sérieux le vidéaste lorsqu'il affirme que l'art doit avoir la vie pour objet et que, «à travers le nouveau médium de la bande vidéo, les deux peuvent désormais être littéralement connexes ${ }^{45}$. Par conséquent, si les séquences dans The Passions ne sont pas assimilables à une image picturale parce qu'elles n'agissent pas en fonction du mécanisme de la représentation, malgré le fait qu'elles induisent en erreur par le biais de la précision réaliste des contours, si elles ne sont

\footnotetext{
${ }^{44}$ S.-I. Dufour, L'image vidéo. D’Ovide à Bill Viola, (préf. de Y. Hersant), Paris, Archibooks, 2008, p. 77.

45 «A conversation. Hans Belting and Bill Viola», art.cit., p. 191.
} 
pas des tableaux vivants, si donc, l'enquête iconologique et contextuelle semble manquer son but quant à la compréhension de la production de B. Viola, il est alors opportun d'inverser la direction de l'enquête et de mettre en évidence la façon dont l'œuvre de l'artiste se définit esthétiquement par rapport à la tradition picturale européenne qu'elle cite pourtant.

Pour formuler une réponse possible, nous trouvons un premier indice dans l'expérience personnelle que le vidéaste - un Américain qui a grandi dans un paysage visuel constitué de choses et non d'œuvres - déclare avoir vécu durant son séjour à Florence entre 1974 et 1976 lorsqu'il travaillait à l'Art/Tapes/22, une période vers laquelle il faut, selon lui, se tourner pour comprendre son travail par la suite ${ }^{46}$. "C'est probablement à cette époque que j'eus mes premières expériences inconscientes d'un art en lien avec le corps car nombre des oeuvres de cette période, des grandes sculptures publiques aux peintures incorporées dans les architectures des églises, ne sont qu'une forme d'installation: une expérience physique, spatiale, à consommer entièrement $»^{47}$. Le patrimoine artistique disséminé dans la ville possède, pour $\mathrm{B}$. Viola, le pouvoir de construire non des lieux tels que les a définis M. Augé, identitaires, relationnels et historiques ${ }^{48}$, mais plutôt ce que j'appellerais un espace diffus dans lequel lui-même - qui en est le premier spectateur - est disséminé.

La façon dont B. Viola s'approche des oeuvres florentines et s'en approprie répond donc aux stimuli qu'elles exercent sur la sensibilité du corps, complexe et synesthésique, et en particulier celle de son corps de performer. Il les perçoit comme des sollicitations qui génèrent des espaces de résonances devant être habités. Plutôt que de les photographier, il passe donc des journées entières à enregistrer le son à l'intérieur des architectures prérenaissantes et affirme :

Lorsque je me rendis compte qu'il y a des schémas d'ondes fixes et qu'il existe une structure de réflexion et de réfraction complètement spatiale, une sorte d'architecture acoustique dans tous les espaces où le son est présent, et qu'il existe un contenu sonore, une note et une fréquence sonore essentiellement, latente dans tous les espaces, alors, je sentis que j’avais identifié un lien vital entre le visible et l'invisible, entre un phénomène interne abstrait et un monde matériel externe. [...] Je commençais alors à utiliser ma caméra comme une sorte de microphone visuel. Je commençais à penser en termes d'enregistrement de "champs" et non de "points de vue". Je me rendis compte qu'il s'agissait toujours d'un intérieur"9.

Ce dernier élément confirme l'importance de la notion d'effacement du cadre fictionnel qui, en tant que tel, séparerait l'intérieur de l'extérieur, l'image de son objet.

Cette déclaration témoigne de la façon dont B. Viola conçoit l'espace visuel de la vidéo; il est pour lui analogue à celui du bourdon, un son maintenu pendant longtemps, sinon pendant l'exécution complète du morceau comme par exemple celui de la cornemuse ou du banjo. Le champ de la vidéo est sonore pour lui :

L'idée d'un champ sonore qui est toujours présent écarte l'attention des objets de la perception pour la porter sur le champ dans lequel la perception est en train d'opérer : un point de vue non spécifique. [...] L'“espace" de la transmission rappelle l'espace acoustique de la cathédrale gothique où tous les sons, leur rapprochement, éloignement ou hauteur n'important pas, semblent venir d'un même espace distant et [être] séparés par la scène

\footnotetext{
46 « Je suis sûr qu’une grande partie de mon travail, dans un sens très large, peut être ramenée à cette période durant laquelle j’ai vécu à Florence, entre 1974 et 1976 » «A conversation. Hans Belting and Bill Viola », art.cit., p. 197).

47 B. Viola, «Risvegliare il corpo con le immagini “potenti” dell'esistenza. Intervista a Bill Viola di Jörg Zutter », première publication in M. L. Syring (dir.), BILL VIOLA. Unseen Images, catalogue de l'exposition itinérante, Düsseldorf, Verlag und Offsetdruckerei R. Meyer, 1992, p. 93-98, titre original « Gesprächt mit Bill Viola ", in Bill Viola. Vedere con la mente e con il cuore, op.cit., p. 85-95, ici p. 86-87.

${ }^{48}$ M. Augé, Non-Lieux. Introduction à une anthropologie de la surmodernité, Paris, Éditions du Seuil, 1992, p. 100.

49 B. Viola, «Risvegliare il corpo con le immagini “potenti” dell'esistenza. Intervista a Bill Viola di Jörg Zutter », art.cit., p. 87.
} 
immédiate, fluctuant dans un ailleurs où le point de vue est devenu l'espace entier ${ }^{50}$

La recherche d'un point de vue non spécifique, que nous pourrions définir comme panoramique, répond à la conception que $\mathrm{B}$. Viola a de l'image elle-même : «Par image, j'entends l'information qui nous arrive à travers la vue, l'ouïe et toutes les modalités sensorielles $»^{51}$. C'est pourquoi la position de H. Belting pour qui les oeuvres du vidéaste confirmeraient que les images migrent d'un médium à un autre, mais qu'aucun média n'est en mesure de créer d'images sans précédents ${ }^{52}$ ne peut pas tenir. Cela ne peut justement pas s'appliquer aux images de B. Viola parce qu'il ne construit pas des images optiques, mais des configurations audiovisuelles dont la vive netteté, comme le reconnaît l'artiste lui-même, «ne concerne pas tant la clarté visuelle ou le détail - il s'agit plutôt d'une fidélité à l'expérience, à l'existence. La sensation pleine de ce qui semble vraiment être là remplit totalement ton corps : ce que l'on perçoit comme si l'on était en train de respirer à ce moment-là. Ce sont les vraies "images" »53. Voilà comment pourrait s'expliquer, sinon se résoudre le paradoxe initial, celui d'une image fortement pathique en tant que telle, mais non destinée à la vue.

Cet espace où se produit l'expérience est, dans la vie quotidienne, lorsque la rencontre bouleversante avec les ouvres d'art n'a pas lieu, l'espace que nous percevons comme celui du paysage dont la forme change selon la position de notre corps, la façon et la vitesse avec laquelle nous nous y déplaçons. Une pièce est différente si nous la considérons la tête en bas, si nous posons nos yeux à la hauteur de la plinthe ou de la tringle, si nous sommes debout à l'arrêt, ou si nous la traversons. Il ne s'agit pas tant ici de simples métamorphoses visuelles, que d'une intensification kinesthésique du corps du sujet - spectateur - lorsqu'il s'étend dans l'espace en le modifiant peu à peu par son propre mouvement, grâce à une collaboration vive et gratuite des sens, comparable à ce que l'on éprouve lors d'une hallucination. Il ne s'agit donc pas tant d'un paysage qui entoure le spectateur comme le ferait un environnement que de l'extension de son corps sensible, le paysage se présentant comme une intensification du corps. C'est principalement pour cette raison que l'espace des images de B. Viola est toujours « interne », un espace qui manque d'ouverture, d'une fenêtre vers l'altérité : il s'agit d'un espace continu, conjoint entre le spectateur et l'œuvre. Ainsi, lorsque le vidéaste écrit que «le véritable lieu dans lequel l'œuvre existe n'est pas la surface de l'écran ou l'espace clos par les murs de la pièce, mais l'esprit et le cœur de la personne qui l'observe $»^{54}$, je crois qu'il faut le comprendre littéralement. Le lieu de l'œuvre est le corps sensible du spectateur. L'ouvre se niche dans son destinataire.

\section{La dissolution du cadre}

Une telle capacité de pénétration esthétique de l'œuvre dépend donc du rôle joué par l'acoustique dans les travaux du vidéaste. Il faut avant tout rappeler que l'espace sonore est un espace dont la source s'éloigne du son : alors que la couleur adhère à l'objet, le son s'en détache et n'est par conséquent pas en mesure de fournir un indice sur la localisation de son

\footnotetext{
${ }^{50}$ B. Viola, «The sound of one line scanning », art.cit., p. 75.

51 B. Viola, «Risvegliare il corpo con le immagini "potenti” dell'esistenza. Intervista a Bill Viola di Jörg Zutter », art.cit., p. 94.

${ }^{52}$ Voir «A conversation. Hans Belting and Bill Viola », art.cit., p. 191.

${ }^{53}$ B. Viola, «La storia, dieci anni (di video) e l'epoca dei sogni », in K. Rae Huffman (dir.), Video: A Retrospective, Long Beach Museum of Art 1974-1984, Long Beach, 1984, titre original : History, 10 Years, and the Dreamtime, (tr. it.), in Bill Viola. Vedere con la mente e con il cuore, op.cit., p. 47-58, ici p. 56.

${ }_{54}$ B. Viola, «Risvegliare il corpo con le immagini "potenti” dell'esistenza. Intervista a Bill Viola di Jörg Zutter », art.cit., p. 95.
} 
origine, éventuellement éloignée du point d'écoute. Le son se répand dans l'espace de vie de l'homme, annulant ses possibilités de le concevoir comme un diagramme de directions. Cela dépend du fait que « tout entendre est présentiel » ${ }^{55}$ - comme était présentiel le mouvement des acteurs dans le cycle The Passions. Dans les ouvres de B. Viola, l'impossibilité de rapporter le son à un objet précis qui en serait la cause - le moteur d'une automobile, les pleurs d'un enfant - est si radicale que la nature même de l'acoustique dont nous faisons l'expérience dans ses vidéos est le résultat d'une hybridation entre du naturel et de l'artificiel, un couple d'opposés que je propose d'utiliser comme alternative à celui que B. Viola lui-même propose par rapport à l'acoustique - visible face à l'invisible. Room for St. John of the Cross (1983) en est l'emblème (fig.32). Le son abstrait que l'on perçoit est le résultat de l'enregistrement du vent qui entrait par la fenêtre ouverte d'une voiture en marche: «Il est beau parce que tu ne peux le situer, il est proche et lointain, bien évidemment il est profond, je pense qu'il s'agit d'un son primordial $»^{56}$. Il faut en outre remarquer que de telles partitions ne sont pas des extraits musicaux et n'incluent pas non plus de paroles produisant un discours, elles sont acousmatiques: lorsque des mots sont présents, dans Sweet Light par exemple, ils ont la valeur de phonè et non de logos. Ce sont des sons de présence qui génèrent une sorte de proximité entre le spectateur et l'image qu'il est apparemment en train d'observer devant lui. L'acoustique exerce une pression sur nous. Nous ne pouvons pas «jeter l'oreille » comme nous jetons un œil en direction d'un objet loin à atteindre.

Fig.32.

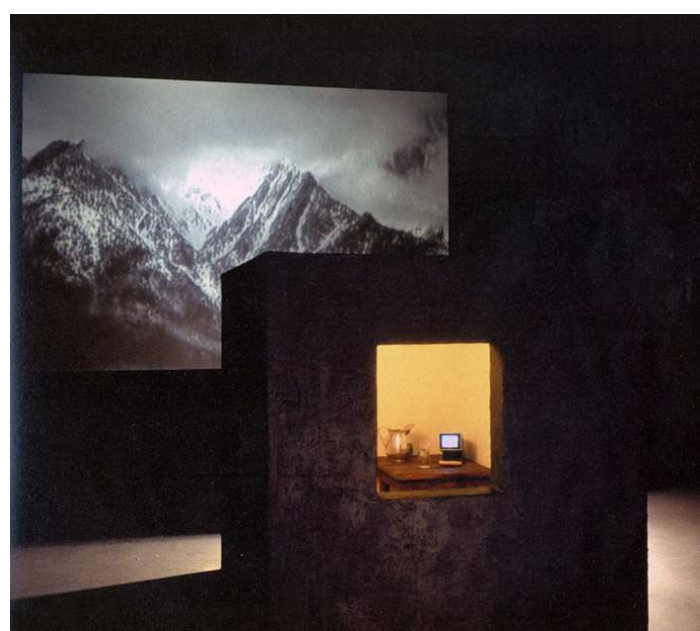

Bill Viola, Room for St. John of the Cross, 1983

in K. Perov, Bill Viola. Visioni Interiori, op.cit., p. 163

Comme l'écrit Valentina Valentini, B. Viola s'emploie à créer des «images puissantes» en mesure de «réveiller le corps du spectateur occidental dominé par l'esprit $\gg^{57}$. Dans ce cas aussi, le vidéaste fait preuve d'une conscience précise aussi bien de son propre projet artistique que de ses implications. En 1992, il affirme dans un entretien retranscrit dans le catalogue de l'exposition romaine de The Passions en 2008, dont on peut par conséquent supposer qu'il est toujours d'actualité, que

dans une époque où le corps en tant qu'instrument authentique de connaissance est tellement ignoré et/ou nié, la dimension physique de ces moyens de communication [électronique〕 a été grossièrement négligée (au cinéma par exemple, en raison de l'aspect prépondérant du

\footnotetext{
${ }_{55}$ E. Straus, « Les formes du spatial», art.cit., p. 27.

${ }_{56}$ Voir l'entretien accordé à M. Kidel, in Bill Viola. The Eye of the Heart: a Portrait of the Artist, op cit..

57 V. Valentini, «L'imago": luce mescolata a tenebre », in Bill Viola. Visioni Interiori, op.cit., p. 126-153, ici p. 129.
} 
littéraire/théâtral). Les intellectuels continuent de considérer avec

beaucoup de défiance les choses qui parlent à l'esprit à travers le corps ${ }^{58}$.

Actuellement, et en rectifiant partiellement l'affirmation de B. Viola, il faut cependant signaler un changement significatif dans le panorama des études philosophiques et esthétiques, toujours plus promptes à prendre en considération le corrélat neurobiologique des émotions et de la pensée elle-même. Si l'on se tient à bonne distance d'éventuelles querelles partisanes, le travail de B. Viola sur ce que j'appellerais les « images incorporées » me semble significatif parce qu'il offre justement l'occasion d'une enquête esthétique concernant non seulement les processus de réception, mais aussi les processus créatifs dont il est possible de mettre en évidence l'efficacité séductrice, dénonçant s'il le faut le pouvoir coercitif, tout en partant des aeuvres elles-mêmes. Certains passages de ses vidéos me semblent confirmer cette ligne directrice, lorsque la qualité acoustique et enveloppante de l'espace produit un résultat analogue à celui d'une cartographie sonore du type de celle que l'on réalise dans les sous-marins, parvenant à subvertir définitivement la règle de la frontalité dans l'art visuel et par conséquent de l'avant par rapport à l'arrière, du dehors par rapport au dedans. Serait-il hasardeux de soutenir que l'art de la vidéo est le résultat de cette révolution du sens de l'espace dont $\mathrm{R}$. Krauss a débattu avec Yves-Alain Bois dans L'Informe, là où en faisant référence aux drippings de Pollock, ils parlent de récupération de la spatialité horizontale, et avec elle animale, commencée avec Cézanne dans Nature morte à l'Amour en plâtre $^{59}$ ? Je ne crois pas.

Examinons cinq séquences. La première se situe à la moitié de Ancient of Days (19791981) : l'œil de la caméra est placé sur la corniche du toit d'un bâtiment élevé qui donne sur une rue à six voies à double sens ; ces dernières traversent la ville et sont encombrées de voitures qui se déplacent dans toutes les directions - disparaissant peu à peu dans un fondu. Cet oeil fixe le point où la route se perd à l'horizon, c'est alors qu'il commence à la suivre (fig.33a), tournant sur lui-même vers le bas à 180 degrés jusqu'à se retrouver au terme de la séquence dans la position inverse à celle de départ, le ciel se trouvant dans la partie inférieure de l'image et la rue dans la partie supérieure (fig.33b). Le mouvement serait celui d'un homme qui, debout, regarderait devant lui et plierait lentement le buste jusqu'à toucher ses genoux avec son visage. Entre temps, la clarté de l'aube s'est transformée en obscurité.

Fig.33a.

\footnotetext{
${ }^{58}$ B. Viola, « In risposta alle domande di Jörg Zutter », art.cit., p. 181.

${ }_{59}$ Y. Alain-Bois, R. Krauss, L'Informe : mode d'emploi, Paris, Centre Georges Pompidou, 1996.
} 


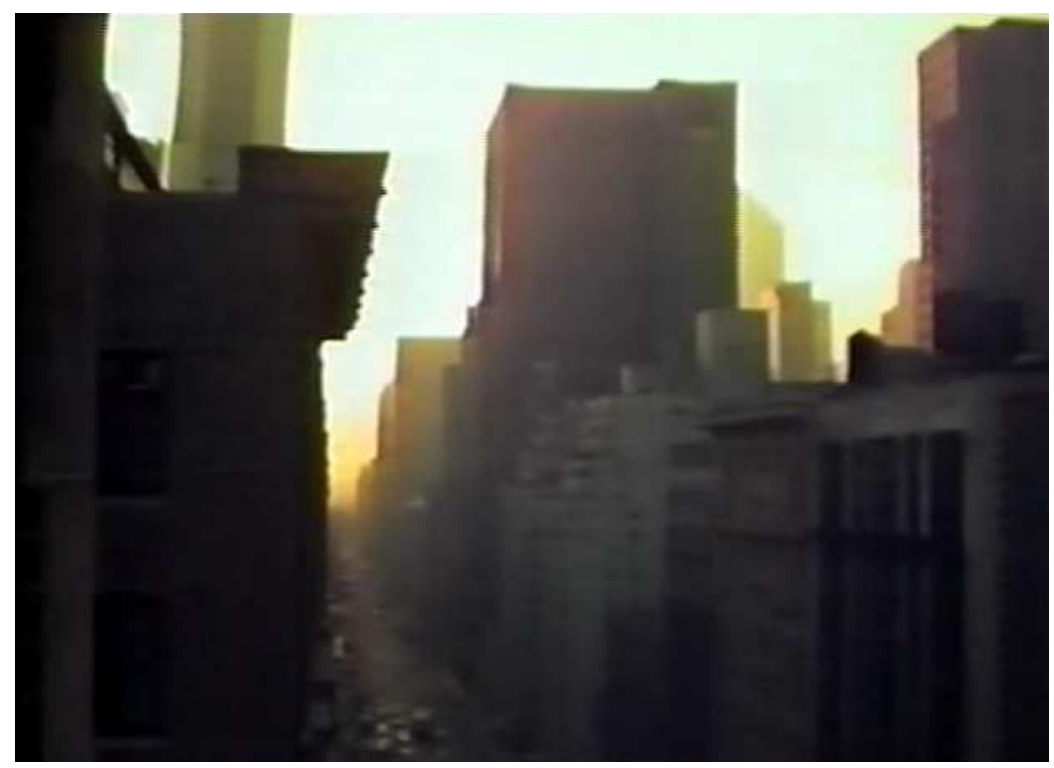

Bill Viola, Ancient of Days, 1979-1981 - photogramme

in B. Viola, Selected Works, 2010, (dvd), Éditions À Voir, 54 mins

Fig.33b.

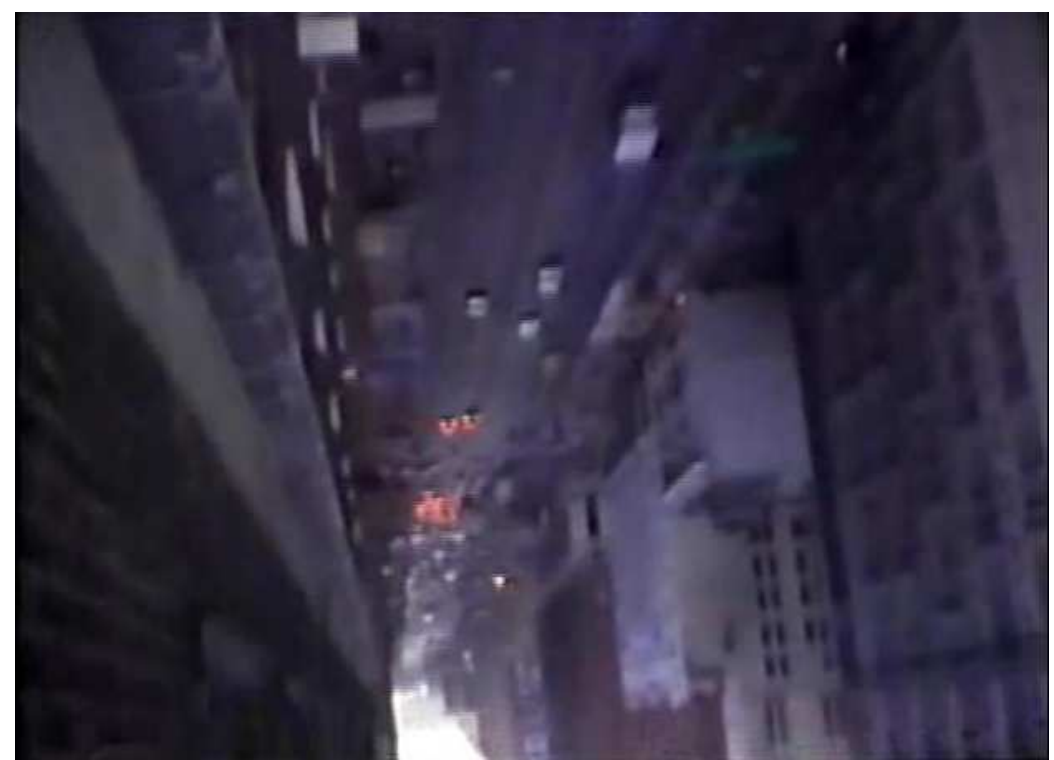

Bill Viola, Ancient of Days, 1979-1981 - photogramme

in B. Viola, Selected Works, 2010, (dvd), Éditions À Voir, 54 mins

La deuxième se trouve dans Chott el-Djerid (A Portrait in Light and Heat) (1979) : au milieu de la vidéo, des figures verticales ondoyantes et de couleur violette défilent de part et d'autre de l'écran. Elles ont la consistance d'une méduse dans l'eau. Elles ne paraissent pas avoir d'avant ni d'arrière, de surface ni de fond (fig.34a). Cette consistance liquide ne rend pas seulement manifeste la façon dont l'expérience de l'image dépasse pour B. Viola son aspect iconique, mais montre aussi à quel point c'est bien l'image qui annule l'élément de la représentation et l'écart visuel qu'il implique. Pour B. Viola, l'image est donc dynamis.

Fig.34a. 


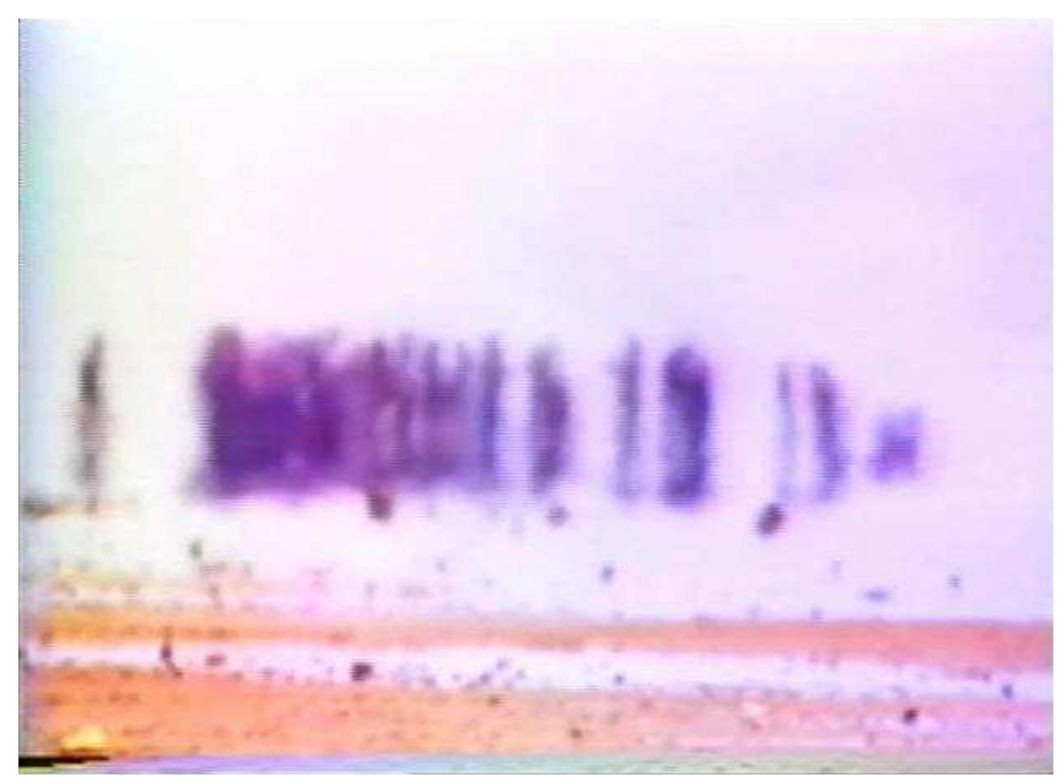

Bill Viola, Chott el-Djerid, 1979 - photogramme

in B. Viola, Selected Works, 2010, (dvd), Éditions À Voir, 54 mins

La troisième est la première scène de $I$ do not know what it is I am like : la caméra, dont le verre de l'objectif est parsemé de gouttelettes, se déplace tout en adhérant au corps de l'opérateur - B. Viola -, à une distance très réduite de la surface d'un lac par rapport à laquelle elle oscille perpendiculairement de façon à cadrer à la fois les pins du bois environnant, qui occupent verticalement la partie gauche de l'écran, et leur reflet, qui en occupe verticalement la partie droite (fig.23h). La caméra tourne progressivement vers la droite et se rapproche du corps de B. Viola jusqu'à cadrer presque exclusivement l'étoffe de son pantalon dont on distingue la trame (fig.23i). Ensuite, la caméra s'éloigne de nouveau sans se redresser, donnant même l'impression de « faire tourner le regard » vers le bas et de courir le long de l'appontement sur lequel se tient le vidéaste, pour s'approcher finalement de la surface de l'eau (fig.23l). De là, la caméra ne s'abaisse pas pour entrer dans l'eau, descendant du haut de l'appontement et maintenant l'axe vertical correspondant à la position naturelle de l'homme; au contraire, elle monte vers l'eau comme elle monterait au ciel (fig.23m). Le seuil de la surface une fois dépassé, la caméra bouge enfin, donnant à voir, dans la partie inférieure de l'écran, l'eau sur laquelle se reflète le fond lacustre composé de pierres et d'algues qui occupe la partie supérieure de l'écran (fig.23n) : les points cardinaux se sont dissous. Dans une autre séquence, B. Viola pose sur une table un verre qu'il vient tout juste de remplir d'eau et dans lequel on voit les particules d'air disparaître et faire progressivement place à une surface limpide et transparente, simplement limitée par les bords du verre. Apparaît alors un bonsaï miniature qui semble contenu dans le verre. B. Viola saisit le verre et le soulève rapidement, le bonsaï reste sur la table : il était derrière le verre, non dedans (figs.23o-p). 


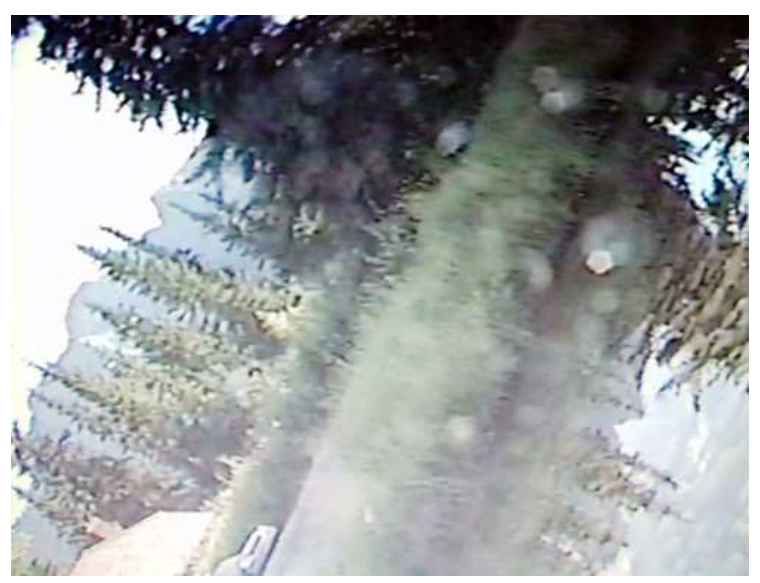

Fig.231.

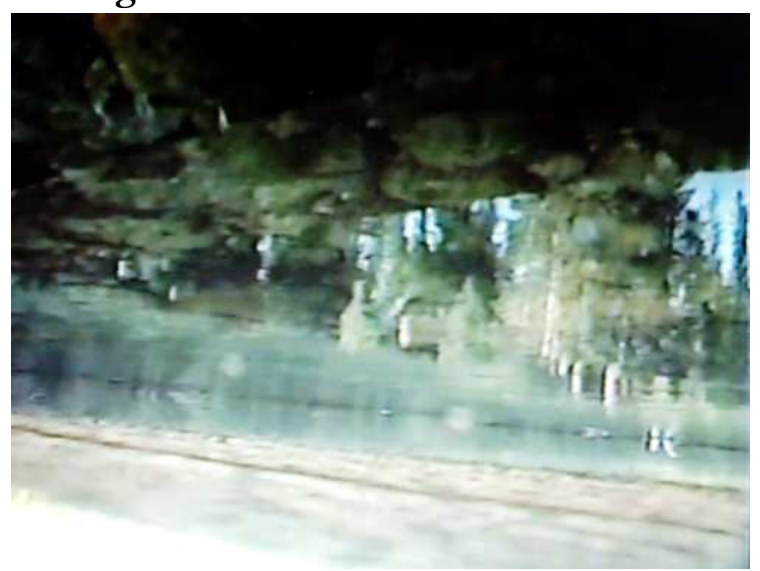

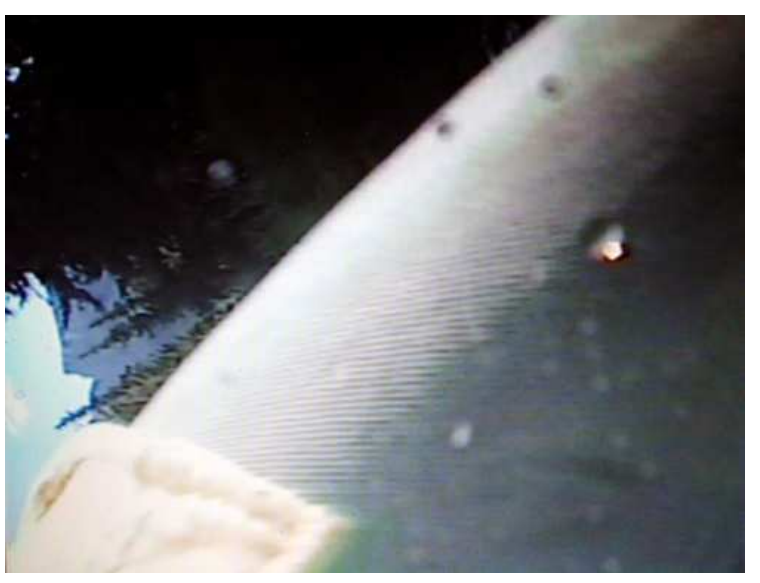

Fig.23m.

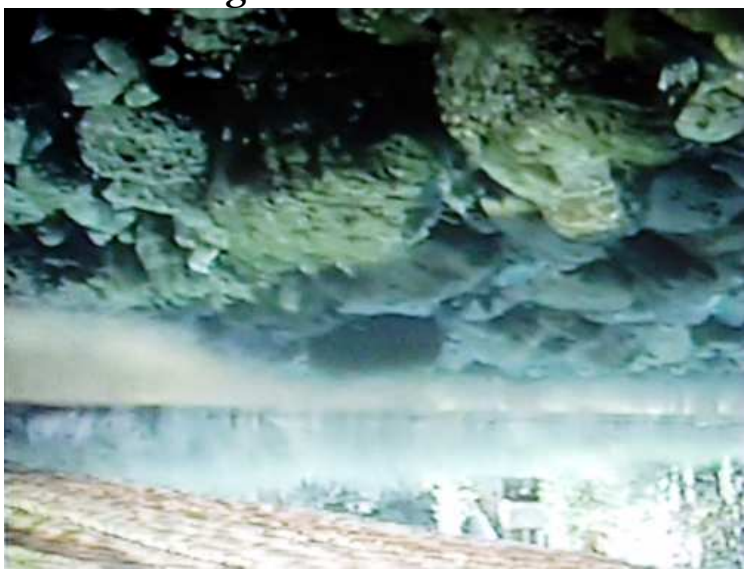

Fig.23n.

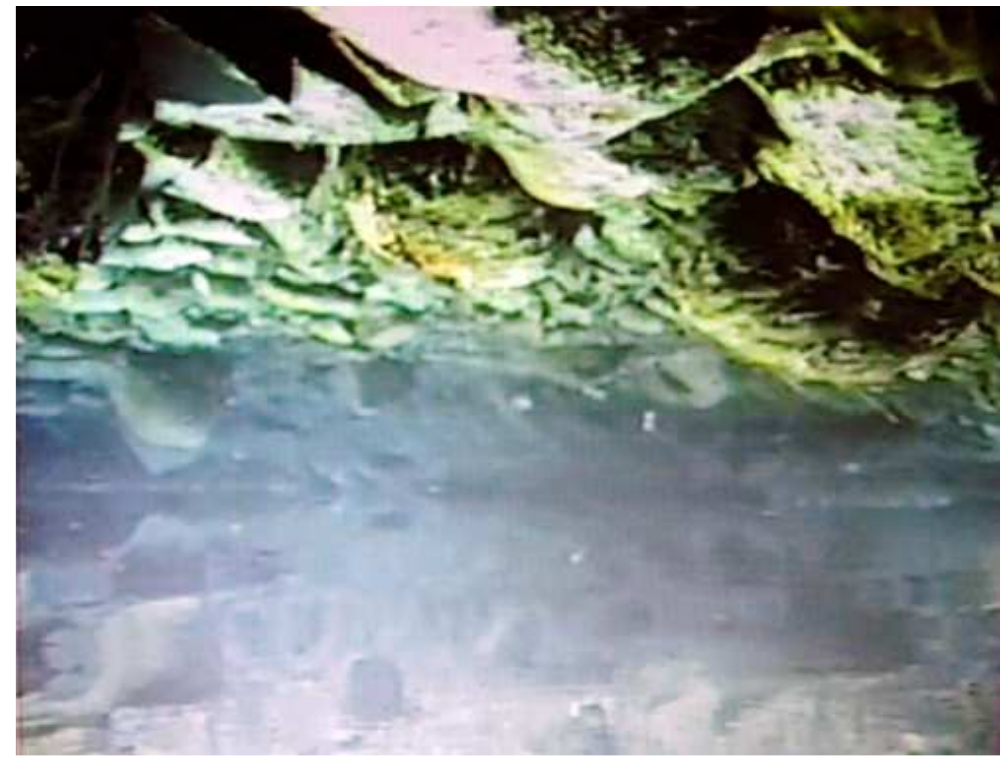

Bill Viola, I do not know what it is I am like, 1986 - photogrammes

in B. Viola, I do not know what it is I am like, [1986] 2006, (dvd), Éditions À Voir, 89 mins 
Figs.230-p.

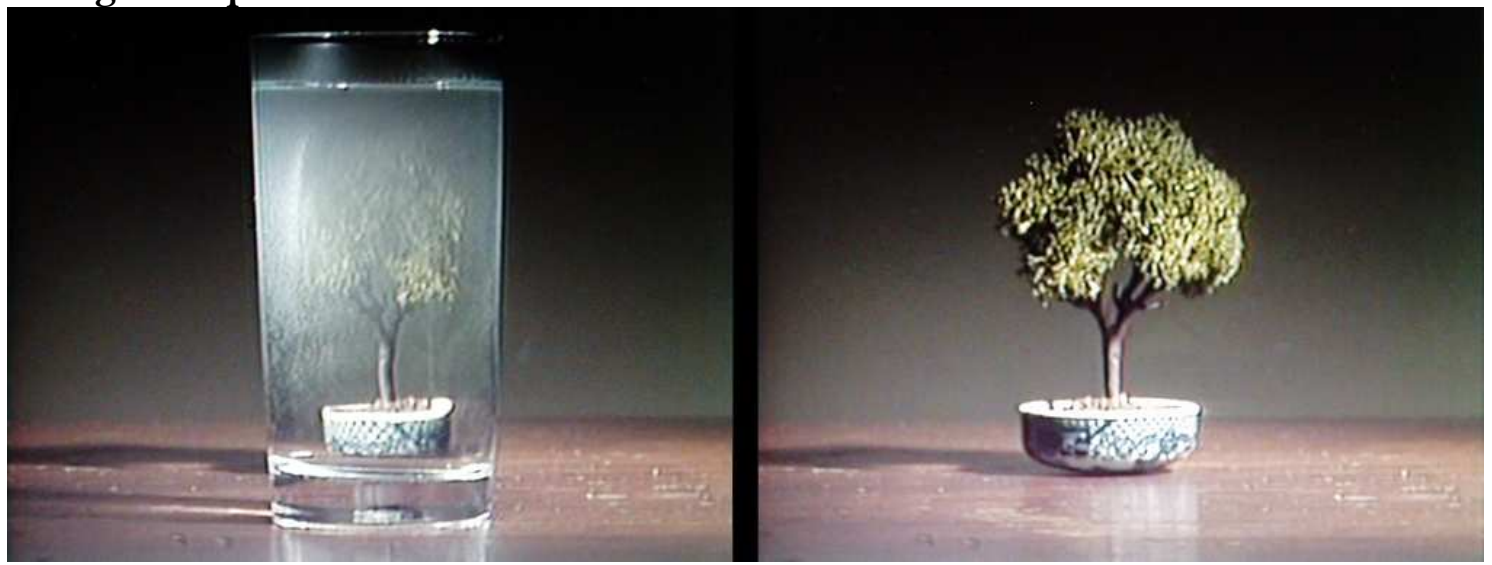

Bill Viola, I do not know what it is I am like, 1986 - photogrammes

in B. Viola, I do not know what it is I am like, [1986] 2006, (dvd), Éditions À Voir, 89 mins

Enfin, dans The Passing (1991), une brève séquence filme certains arbres en contreplongée sans cadrer la base des troncs (fig.35a). De cette façon, les branches, qui se développent à l'évidence en s'amincissant vers le haut, perdent la capacité de fournir une indication de direction utile pour s'orienter: où se trouve le haut? Le bas? Si je voulais monter, quelle direction devrais-je suivre?

Fig.35a.

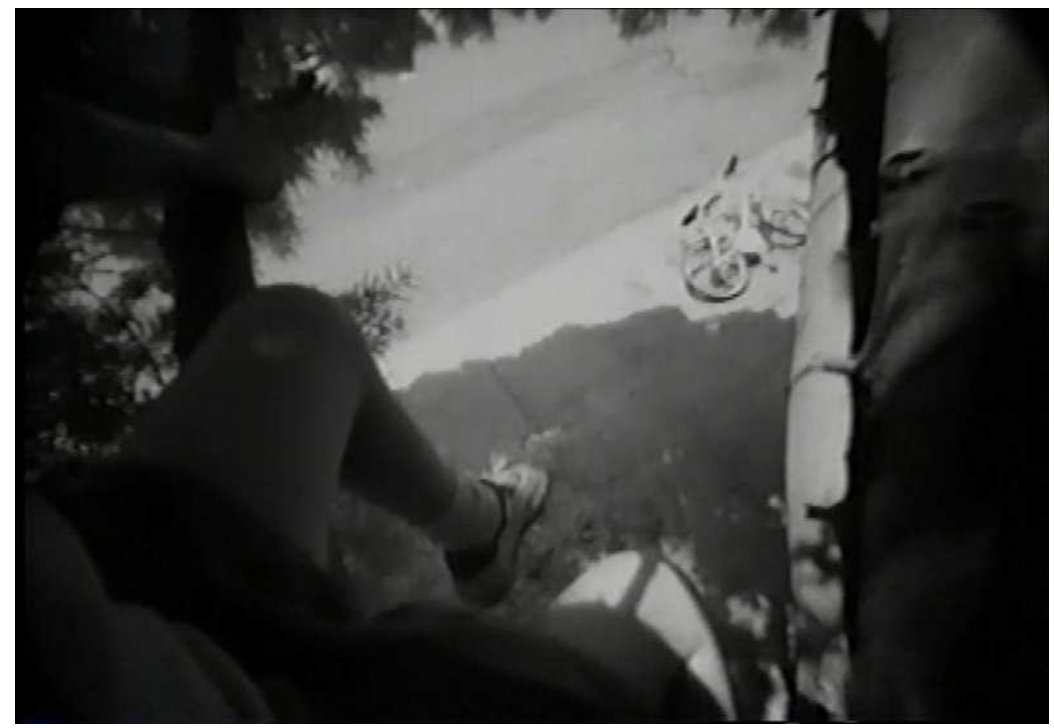

Bill Viola, The Passing, 1991 - photogramme

in B. Viola (dir.), The Passing, [1991] 2006, (dvd), Éditions À Voir, 54 mins

Cette annulation du seuil de la représentation par le biais de l'excitation sensorielle se réalise souvent à travers la réflexion d'un corps dans une goutte d'eau ou une surface mouillée, ou bien à travers la suspension d'une réverbération lumineuse. Plus que des images, ces phénomènes optiques, s'approchant d'une réalisation technologique des couleurs physiologiques, forment des impressions visuelles du temps qui passe et dont le flux aqueux serait le prototype. C'est le cas dans la séquence de la barque de pêcheurs de Hatsu-Yume où l'empreinte lumineuse des lumières électriques du bateau de pêche suspendue dans l'obscurité d'un ciel nocturne (fig.21c), et celle des néons de la ville sous la pluie (fig.21d), restent au milieu de l'air et construisent le corps filamenteux du temps.

Fig.21c. 


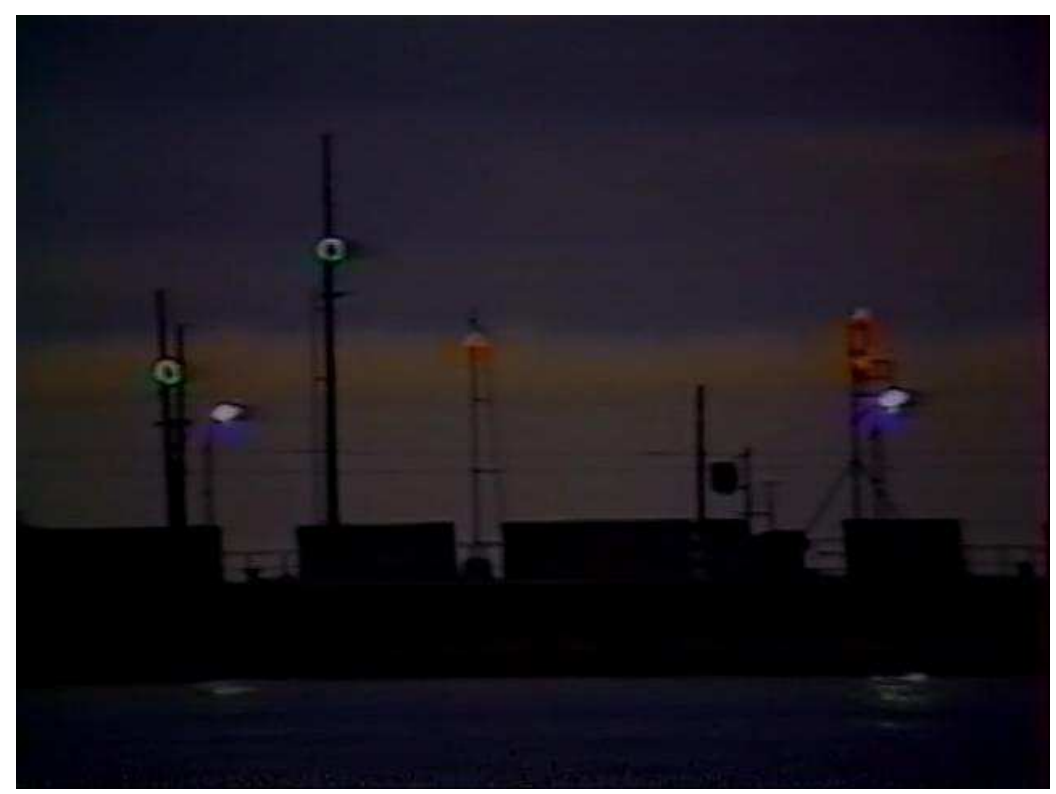

Bill Viola, Hatsu-Yume First Dream, 1981 - photogramme

In B. Viola, Hatsu-Yume First Dream, [1981] 2006, (dvd), Éditions À Voir, 56 mins

Fig.21d.

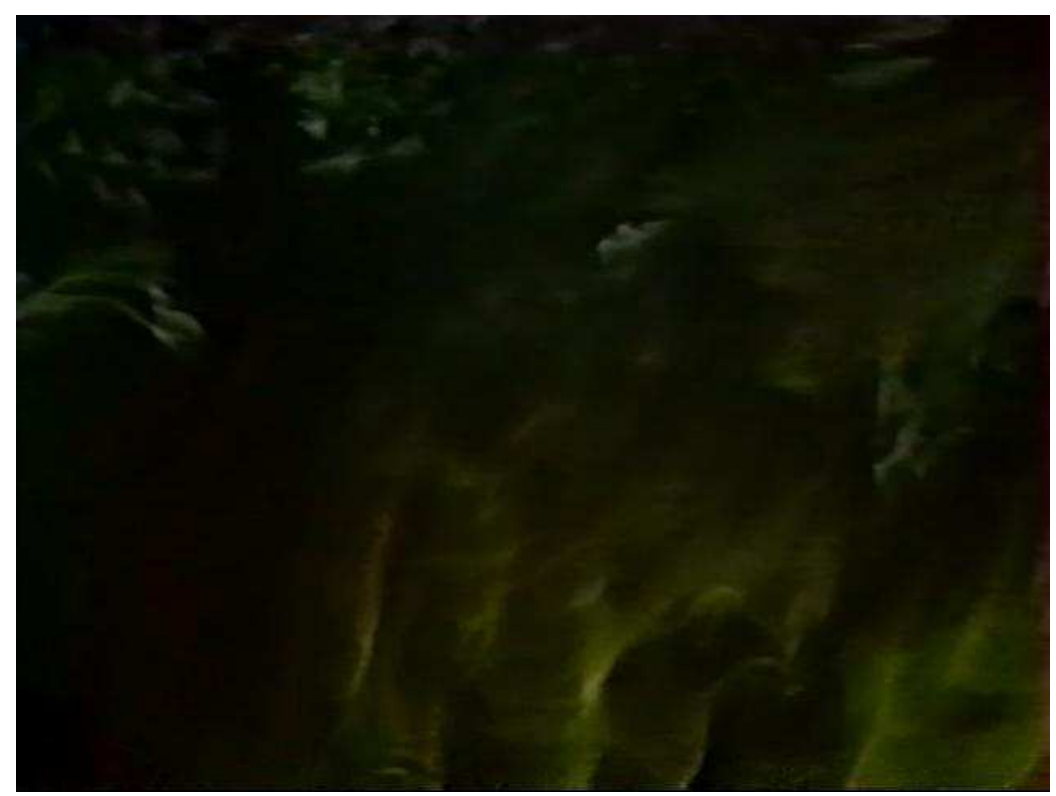

Bill Viola, Hatsu-Yume First Dream, 1981 - photogramme

in B. Viola, Hatsu-Yume First Dream, [1981] 2006, (dvd), Éditions À Voir, 56 mins

La dissolution de la frontalité et de la succession temporelle est également mise en scène dans l'une des rares actions qui surviennent dans les vidéos précédant The Passions : la marche errante dans un espace vide, comme si l'on avançait aveuglément. Arrêtons-nous sur The Passing et Chott el-Djerid. Dans le premier, comme si nous étions installés dans les yeux de B. Viola, nous voyons, en vue plongeante, les jambes et les bras d'un homme assis dans un paysage rocheux et aride. Il se lève et marche presque jusqu'à l'essoufflement. Nous voyons son ombre projetée sur le sol devant lui et distinguons ainsi une petite caméra placée audessus de son crâne. Elle tourne de façon désordonnée dans plusieurs directions en suivant les mouvements de la tête, donnant l'impression que l'espace environnant l'homme qui marche est vaste. À la fin, B. Viola tombe et nous tombons avec lui, le visage dans le sable (figs.35b-c). Dans la seconde vidéo, un point noir au centre de l'image avance suivant un mouvement indéchiffrable et hésitant vers la surface de l'écran en traversant une étendue 
désertique, prenant de plus en plus des traits humains tout en demeurant fantasmatique ${ }^{60}$ (fig.34b).

Fig.35b.

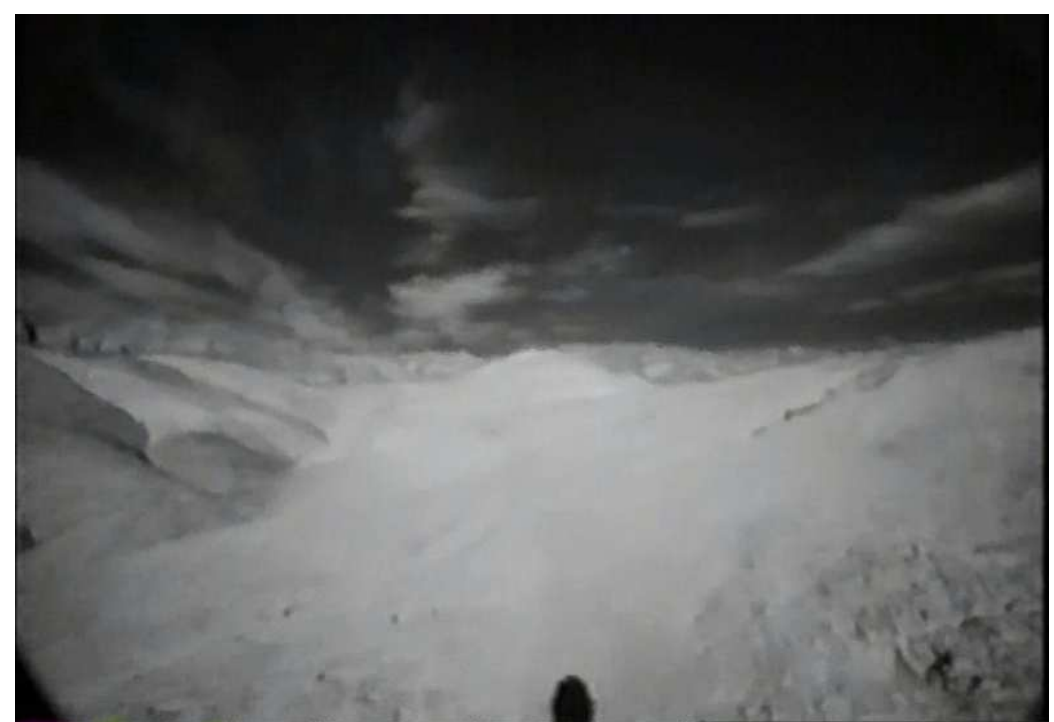

Bill Viola, The Passing, 1991 - photogramme

in B. Viola, The Passing, [1991] 2006, (dvd), Éditions À Voir, 54 mins

Fig.35c.

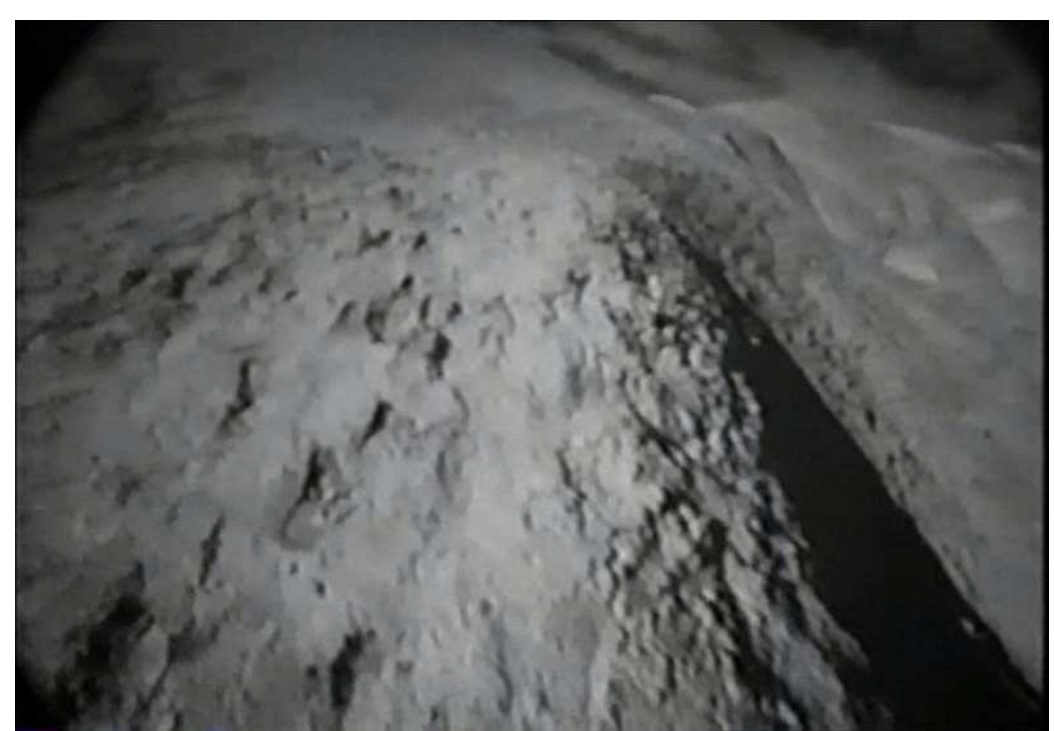

Bill Viola, The Passing, 1991 - photogramme

in B. Viola, The Passing, [1991] 2006, (dvd), Éditions À Voir, 54 mins

Fig.34b.

${ }^{60} \mathrm{~B}$. Viola a d'ailleurs qualifié cet espace qui s'écarte autour de ce point en mouvement d'« onirique »; en effet, l'espace du rêve est privé de point de vue. Voir Visioni Interiori, op.cit., p. 158. 


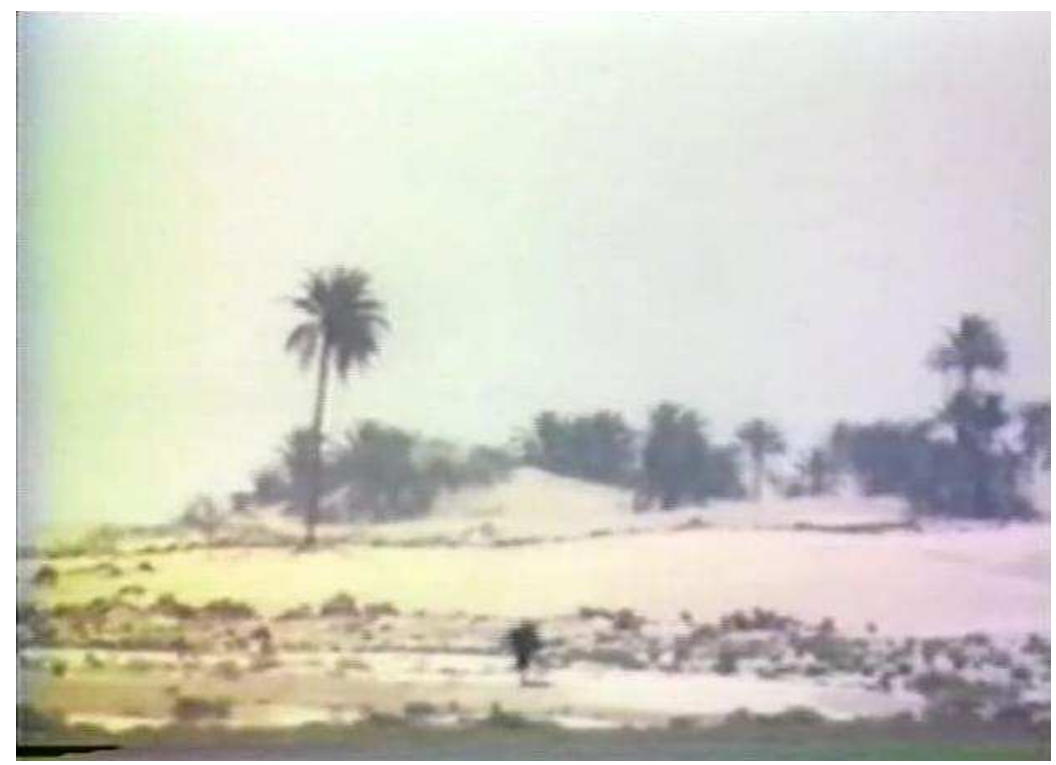

Bill Viola, Chott el-Djerid, 1979 - photogramme

in B. Viola, Selected Works, 2010, (dvd), Éditions À Voir, 54 mins

Ce que J.-P. Fargier a écrit est opérant pour toutes ces séquences :

Tout est dans le champ. Il n'y a pas de hors-champ. Voilà encore une différence fondamentale entre vidéo et cinéma. L'espace cinématographique est non seulement un mais infiniment extensible. [...] La vidéo ne survole rien. Elle explore des plis, des replis intérieurs. Au départ tout est là. [...] Rien ne peut arriver du dehors. Ce qui surgit était là. À tout moment le champ peut s'ouvrir, s'ouvre, extrait de lui-même un autre champ. Rien ne vient du dehors, ne viendra : pas besoin de guetter, d'attendre, de surveiller les bords. C'est au-dedans que tout se passe61.

On pourrait penser que cela vaut pour les bandes vidéo, non pour les installations pour lesquelles Otto Neumaier affirme que «nous ne sommes pas en mesure de trouver une place pour tout ce qui est projeté dans un tel espace. Où que se pose le regard, il y a toujours quelque chose qui survient hors de notre champ visuel, même derrière nous ${ }^{62}$. Toutefois, cette éventualité ne nous concerne pas vraiment puisque nous y sommes complètement absorbés. Comme l'écrit Félix Burda Stengel qui a comparé la spatialité baroque construite par Andrea Pozzo dans l'église Sant'Ignazio à Rome et l'espace des installations de certains vidéastes parmi lesquels B. Viola :

L'art de l'installation est un art spatial. [...] En franchissant le seuil d'une installation, le spectateur traverse en quelque sorte le cadre albertien et entre dans l'espace de l'art. Et il devient ainsi une partie de l'œuvre d'art ; le mouvement à travers l'installation fait que le corps du spectateur se déplace dans l'œuvre et la modifie. Chacun perçoit l'œuvre différemment, en fonction du parcours qu'il y entreprend. En entrant dans l'espace de l'art, le spectateur n'est pas seulement dans une action de transformation de l'œuvre car, par cet acte, l'œuvre advient en tant que telle. Son existence dépend en quelque sorte de la "participation au jeu" du spectateur63.

Il se produit donc la perte d'un point de vue reconnaissable et avec cela la perte de la position du spectateur. Si la perspective, dans toutes ses manifestations et oblitérations, crée un espace homogène et isomorphe dans lequel l'image s'organise selon un rapport

\footnotetext{
${ }^{61}$ J.-P. Fargier, « The reflecting pool de Bill Viola », art..cit., p. 29.

62 O. Neumaier, «Space, time, video, Viola », in C. Townsend (éd.), The Art of Bill Viola, op.cit., p. 46-71, ici p. 57 .

${ }^{63}$ F. Burda-Stengel, Andrea Pozzo et l'Art Video. Déplacement et point de vue du spectateur dans l'art baroque et l'art contemporain, (préf. de H. Belting, tr. de l'allemand par H. Wagner), Paris, Isthme Éditions, 2006, p. 111.
} 
figure/fond, ici, l'espace auquel nous avons accès est étendu et inclusif, quelle que soit l'ouverture de l'horizon qui nous est montré. Dans les vidéos, cela dépend de la proximité spécifique instaurée par la caméra avec les corps dont elle enregistre la présence. Dans le cycle, cela dépend du fait que le spectateur est évincé par ce regard, dont nous avons parlé, qui lui est destiné et lui provoque pourtant «la sensation d'être ignoré ». B. Viola affirme en effet que le but implicite de nombre de ses

efforts, y compris le développement technologique, est le déracinement du taux de bruit de fond dans le signal, à savoir la réalisation finale de l'état d'une transparence ultime dans laquelle nous ne percevons aucune différence entre la simulation et la réalité, entre l'autre et nous-mêmes. Nous pouvons penser à deux amants liés par l'extase de l'étreinte. Nous pouvons penser aux suggestions futuristes sur la stimulation directe du cerveau pour susciter expériences et souvenirs. Nous pouvons penser aux expériences de la drogue - le LSD comme projection d'un film intérieur ${ }^{64}$.

Nous retrouvons une semblable élimination de la différence dans la façon dont la caméra fait intrusion dans la bouche béante de B. Viola dans The Space Between the Teeth (1976) (fig.36), dans la façon dont elle pénètre la tranche de melon dans Anthem (1983) - une sorte d'échographie interne d'un espace constitué de filaments, de petites ornières que les graines qui se sont détachées ont laissées vides et des protubérances de celles qui s'y trouvent encore - ou dans la façon dont elle s'approche de la peau du visage endormi de B. Viola couché dans un lit dans The Passing (fig.35d). La caméra est une main qui touche sans adhérer au corps qu'elle approche. C'est cette forme particulière de proximité que B. Viola, me semble-t-il, souhaite décrire lorsqu'il affirme que

l'idée que la caméra est une espèce de succédané de l'œil, une métaphore de la vision, ne dit pas assez. La caméra ne ressemble que vaguement au mécanisme de l'œil, et certainement pas au type de vision stéréoscopique que l'œil humain - intégré au cerveau - possède. Dans le fonctionnement, elle agit plutôt comme quelque chose de semblable à ce que nous appelons conscience ou attention humaine ${ }^{65}$.

Fig.36.

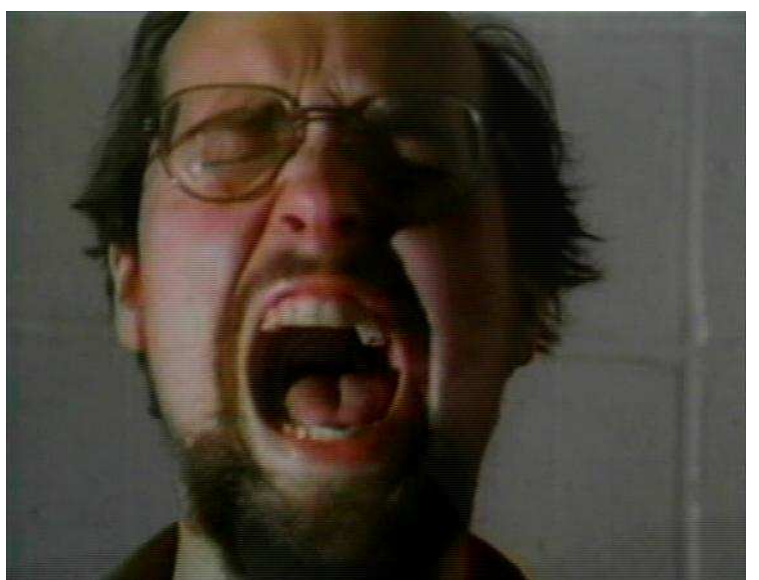

Bill Viola, The Space between the Teeth, 1976 - photogramme

in M. Kidel, Bill Viola. The Eye of the Heart : a portrait of the artist, 2004, (dvd), Calliope Media Production, BBC et Arte France, 59 mins

Fig.35d.

\footnotetext{
${ }^{64}$ B. Viola, «Perception, technologie, imagination et paysage (1991)», in N. Magnan (dir.), La Vidéo, entre art et communication, Paris, École nationale supérieure des Beaux-Arts, 1997, p. 151-157, ici p. 156.

${ }_{65}$ B. Viola, «Sight unseen. Enlightened squirrels and fatal experiments », Video 80 Magazine, printemps 1982, p. 31-33.
} 


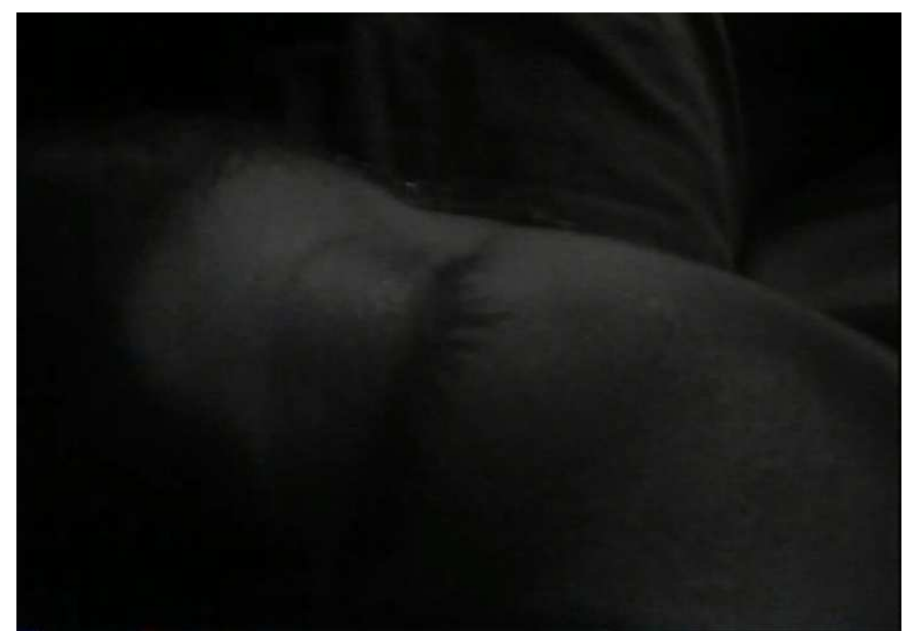

Bill Viola, The Passing, 1991 - photogramme

in B. Viola, The Passing, [1991] 2006, (dvd), Éditions À Voir, 54 mins

En définitive, l'image n'est pas destinée à la vision, mais à la perception sensible du corps. Soit elle se transforme en espace, soit, en tant que cadre optique bidimensionnel, elle devient un objet mort. Nous en trouvons la déclaration poétique dans la séquence finale de The Space Between the Teeth: le cadrage du long couloir vide se fixe pour un instant en une image arrêtée qui se détache de l'écran, tombant en arrière et finissant dans la mer accompagnée par le bruit sourd d'un corps lourd; là, elle flotte en surface jusqu'à ce qu'une vague l'emporte ${ }^{66}$.

Le rendu visible des environnements que B. Viola filme dans ses vidéos (déserts, forêts, bois, prairies, champs cultivés, montagnes, routes asphaltées) semble lui aussi représenter l'expérience de l'espace que permet la vidéo plutôt qu'une sorte de vue naturelle. Une telle expérience répond à la caractéristique technologique que B. Viola reconnaît à son propre médium :

Technologiquement, la vidéo vient du son (l'électromagnétique), c'est pourquoi l'apparenter au cinéma est trompeur, dès lors que le cinéma et son prédécesseur, le processus photographique, font partie d'une branche complètement différente de l'arbre généalogique (le chimique-mécanique). Le caméscope, en tant que dispositif électronique conducteur d'énergie physique par impulsions électriques, a, à l'origine, une ressemblance plus étroite avec le microphone qu'avec la caméra. La première étude télévisuelle était un hybride entre la radio, le théâtre et le cinéma. Ses images existaient dans le présent ${ }^{67}$.

Cet espace qui vient rencontrer l'activité esthésique du spectateur est finalement dépossédé de son cadre, contrairement à celui qui s'ouvrait derrière la fenêtre albertienne.

L'hypothèse que j'avance est que dans le travail de B. Viola, le cadre de la fiction picturale et théâtrale explose à la fois en tant que fonction qu'en tant qu'artefact matériel. Le cadre a pour fonction de mettre entre parenthèses ce qu'il circonscrit, en interrompant la contiguïté entre les corps en image et ce qui les entoure, distinguant ainsi le milieu dans lequel le spectateur peut intervenir et celui qu'il protège en revanche de son ingérence. Il s'agit par conséquent d'un dispositif qui, d'un côté, caractérise la représentation comme découpage, et de l'autre, règle l'intention du récepteur dont la perception est simplifiée et hiérarchisée. Cette fonction d'exclusion est désactivée dans la production de B. Viola.

Ensuite, en tant qu'artefact, le cadre fictionnel est intégré à l'image comme un bruit qui entoure et contient l'alternance des cadrages pendant qu'il s'infléchit en se transformant

\footnotetext{
${ }^{66}$ Pour une description matérielle de la scène, voir R. Bellour et B. Viola, «An interview with Bill Viola », art.cit., p. 103.

${ }^{67}$ B. Viola, « The sound of one line scanning », art.cit., p. 73.
} 
en son. Dans Anthem, l'alternance de lieux urbains, naturels et industriels est associée au bruit continu qui accompagne la vidéo et la caractérise comme un unicum. Ce bruit ressemble à la fois à celui d'une usine en activité, d'une scie électrique, au cri d'un loup et au chant d'un muezzin. Une qualité sensible hybride que nous retrouvons aussi dans Chott-el-Djerid où, à nouveau, l'origine possible des bruits est indépendante de ce qui se produit dans l'image, sauf pour le bruit du rocher jeté dans la mare par B. Viola qui entre dans le cadrage en nous tournant le dos et se dirige, d'un pas décidé, vers l'étendue d'eau au point qu'il semble presque repousser physiquement d'un coup sec la propagation de ce bruit dans l'espace. Dans Migration, le son se fera plus métallique et comparable à un coup de cloche et précède le moment où l'image se clarifie, l'action scénique devient reconnaissable; il accompagne tout le développement de la vidéo sans lien indiciaire direct avec le récit et moins encore avec la chute des gouttes d'eau. Ce faisant, B. Viola enrichit esthétiquement le principe narcissique de l'art vidéo identifié par R. Krauss.

«Il y a quelque chose d'immortel dans un écho ${ }^{68}$ affirme le vidéaste qui, remplaçant l'espace visuel par l'espace acoustique, substitue finalement l'écho au reflet, interrompant le jeu d'identité et de différence que ce dernier instaure et ouvrant plutôt vers une extension du sens primordial de soi-même. Pour cette raison, ce n'est plus l'œil, mais le corps entier du spectateur qui devient le destinataire de la vidéo. Si Walter Benjamin a pu écrire en 19351936 que le médium photographique avait modifié l'histoire de la perception en libérant la main de ses tâches artistiques qui furent dès lors réservées à l'œil, donnant le départ à la reproductibilité technique de l'œuvre ${ }^{69}$, aujourd'hui le médium de la vidéo change l'organisation de la perception en transformant la réception visuelle en une réception synesthésique. L'image sensible explose dans le corps du spectateur et s'inscrit en lui, changeant de cette façon la nature même de l'œuvre d'art vidéo qui n'est pas reproductible dès lors qu'elle ne peut exister qu'en tant qu'expérience vécue. L'incorporation de l'œuvre a pour corrélat la dématérialisation de son support et en même temps, il semble - pour le moins - dissimuler un quelconque enracinement historique qui ne serait pas la pure attestation de présence du récepteur ramené à un présent permanent, comme nous l'avons suggéré au début. Cela explique aussi selon moi la «facilité » avec laquelle les spectateurs reçoivent les vidéos de $\mathrm{B}$. Viola: le vidéaste est cohérent avec la transformation synesthésique et kinesthésique associée à la production d'image d'aujourd'hui, comme à leur réception. Qu'une telle transformation soit à son tour un phénomène culturel, cela me semble indubitable, mais plus que l'antagonisme entre le paradigme culturel et un paradigme biologique quelconque, il m'a semblé opportun de m’interroger sur la façon dont l'accentuation de la puissance esthésiologique d'une image intervient justement dans l'économie de la fiction et de la représentation artistique.

Chiara Cappelletto est maître de conférence en esthétique à l'université de Milan. Docteur en philosophie depuis 2003, sa thèse analysait la « vision synoptique » chez Ludwig Wittgenstein et sa dette envers la morphologie goethéenne. Elle a obtenu en 2003 son DEA à l'EHESS avec un travail centré sur la notion de Darstellung chez Aby Warburg et Wittgenstein, dont elle a développé la pensée esthétique pendant une bourse de recherche post-doctorale au Département de Philosophie de l'université de Milan en 2005/2006. Pendant le spring term 2009/2010, elle a obtenu un poste d'Assistant Research Fellow à l'Italian Academy for Advanced Studies in America à l'université Columbia de New York. Dans son domaine de recherche elle

\footnotetext{
68 Ibid., p. 71-72.

${ }_{69} \mathrm{~W}$. Benjamin, L'Cuvre d'Art à l'époque de sa reproductibilité technique (extrait de CEuvres III, I), (tr. de l'allemand par M. de Gandillac), Paris, Éditions Allia, 2003, p. 11.
} 
privilégie la philosophie de l'image et l'esthétique théâtrale, auxquelles elle a consacré plusieurs essais développant en particulier la notion de théâtre comme objet esthétique et le rôle de la fiction dans l'expérience du spectateur. Parmi ses publications récentes: Neuroestetica. L'arte del cervello (Laterza, 2009); Il rito delle pulci. Wittgenstein morfologo (Il Castoro, 2004), IXe prix Castiglioncello pour la philosophie dans la section « Giovani studiosi »; Figure della rappresentazione. Gesto e citazione in Bertolt Brecht e Walter Benjamin (Mimesis, 2002). Elle a édité l'ouvrage suivant: Scena e dramma. Per una fenomenologia del teatro, par Waldemar Conrad (CLUEB, 2008). 